\title{
LA COMPETIZIONE MAGGIORITARIA: LE ORIGINI ELETTORALI DEL PARLAMENTO DIVISO
}

\author{
di Stefano Bartolini e Roberto D'Alimonte
}

\section{I risultati}

Maggioritario, ma non troppo. Così si può riassumere sinteticamente il risultato delle elezioni politiche del 27 marzo 1994. Non c'è dubbio infatti che la componente maggioritaria del sistema elettorale abbia funzionato, ma è altrettanto vero che da sola non è bastata ad impedire uno degli effetti più significativi e sorprendenti di queste elezioni: un Parlamento diviso. Camera e Senato hanno due maggioranze diverse, o meglio, la Camera ha una maggioranza e il Senato no. Senza la componente proporzionale, il sistema maggioritario avrebbe prodotto, coeteris paribus, maggioranze nette sia alla Camera che al Senato (Tab. 1).

Nonostante ciò, il destino parlamentare dei diversi schieramenti è stato deciso nell'arena maggioritaria. Queste elezioni sono state elezioni maggioritarie. La stessa differenza tra Camera e Senato, come vedremo, ha le sue origini non solo nella componente proporzionale del sistema elettorale, ma anche nel fatto che l'esito della competizione maggioritaria è stato diverso al Senato rispetto alla Camera. Per varie ragioni, i Progressisti sono stati più competitivi al Senato. Ed è qui, oltre che nelle caratteristiche intrinseche del sistema elettorale adottato, che dobbiamo cercare le ragioni del Parlamento diviso ${ }^{1}$. Ma andia-

Desideriamo ringraziare Alessandro Chiaramonte e Massimiliano Miglio per la preziosa collaborazione prestata in diverse fasi di questa ricerca. Un ringraziamento va anche a Aldo Di Virgilio per l'assistenza fornita nella raccolta dei dati sull'appartenenza partitica dei candidati dei diversi schieramenti.

1 L'esistenza di due maggioranze diverse alla Camera e al Senato o, meglio, l'assenza di una maggioranza di destra al Senato può essere spiegata facendo riferimento a numerosi fattori, soprattutto tenendo conto del fatto che sono pochi i seggi mancanti per arrivare alla soglia di maggioranza. In breve, se lo scorporo al Senato fosse stato parziale e non totale; se i Progressisti non avessero ottenuto al Nord una percentuale di 
TAB. 1. Risultati complessivi per aggregazioni politiche e per tipo di seggi

\begin{tabular}{|c|c|c|c|c|c|c|c|c|c|c|c|c|c|}
\hline & & \multicolumn{3}{|c|}{ Progressisti } & \multicolumn{3}{|c|}{ Poli ${ }^{1}$} & \multicolumn{3}{|c|}{ Patto per l'Italia } & \multicolumn{3}{|c|}{ Altri } \\
\hline & & S.M. & S.P. & S.T. & S.M. & S.P. & S.T. & S.M. & S.P. & S.T. & S.M. & S.P. & S.T. \\
\hline \multirow[t]{2}{*}{ Camera } & $\mathrm{Nr}$. & 164 & 49 & 213 & 302 & 64 & 366 & 4 & 42 & 46 & 5 & 0 & 5 \\
\hline & $\%^{2}$ & 34,5 & 31,6 & 33,8 & 63,6 & 41,3 & 58,1 & 0,8 & 27,1 & 7,3 & 1,1 & 0,0 & 0,7 \\
\hline \multirow[t]{2}{*}{ Senato } & $\mathrm{Nr}$. & 96 & 26 & 122 & 128 & 28 & 156 & 3 & 28 & 31 & 5 & 1 & 6 \\
\hline & $\%^{2}$ & 41,4 & 313 & 38,7 & 552.2 & 33,7 & 495 & 1,2 & 33,7 & 9,8 & 2,2 & 1,2 & 1,9 \\
\hline
\end{tabular}

Legenda: S.M. seggi maggioritari; S.P. seggi proporzionali; S.T. seggi totali.

1 Polo della Libertà $(\mathrm{Pl})$, Polo del buon governo $(\mathrm{Pbg})$ e loro varianti (compresa la Lista Pannella alla Camera e la Lista Pannella-Riformatori al Senato).

$2 \%$ di seggi calcolata sul totale di ciascuna categoria S.M., S.P., S.T.

mo con ordine, cominciando da un esame elementare, ma essenziale dei risultati relativi ai tre schieramenti che si sono contesi la vittoria nei collegi (Tab. 1).

1. Sia alla Camera che al Senato i Poli (Polo delle Libertà e Polo del buon governo e loro varianti) hanno ottenuto la maggioranza assoluta dei seggi uninominali: il 63,6\% alla Camera e il $55,2 \%$ al Senato. Ma la componente proporzionale del sistema ha attenuato questo risultato tanto che al Senato la maggioranza assoluta dei seggi uninominali diventa minoranza (seppur di poco) dei seggi complessivi².

2. Il Patto per l'Italia (Patto Segni e Partito Popolare Italiano) è stato assolutamente non competitivo nell'arena maggioritaria sia alla Camera (4 seggi) che al Senato ( 3 seggi), e deve la sua sopravvivenza parlamentare all'effetto riequilibratore della componente proporzionale che è stato più sensibile al Senato che alla Camera a causa del diverso effetto dello «scorporo».

seggi più elevata al Senato rispetto alla Camera, oggi non parleremmo di Parlamento diviso. A nostro avviso però il fattore più importante, e quello su cui concentriamo la nostra analisi, è la differenza nel rendimento elettorale dei Progressisti al Senato, soprattutto nel Sud.

2 Con l'uso della tecnica della simulazione A. Chiaramonte (1994) ha dimostrato efficacemente come lo scorporo abbia determinato questo effetto. Senza scorporo o con lo scorporo parziale della Camera, lo schieramento di destra (i Poli) avrebbe oggi la maggioranza assoluta dei seggi anche al Senato. 
3. I Progressisti hanno perso in entrambe le camere, ma hanno ottenuto al Senato un risultato notevolmente migliore rispetto alla Camera soprattutto nella arena maggioritaria dove sono arrivati al $41,4 \%$ dei seggi rispetto al $34,5 \%$ della Camera. Per i Progressisti dunque la componente proporzionale ha avuto un effetto neutrale visto che la percentuale dei seggi proporzionali nelle due camere è praticamente la stessa e corrisponde, tra l'altro, sostanzialmente alla percentuale dei voti proporzionali ottenuti da tutte le liste di sinistra appartenenti a questo schieramento ${ }^{3}$.

A livello di grandi aggregazioni politiche, la competizione maggioritaria ha quindi prodotto un esito sostanzialmente bipolare. Questo non vuol dire naturalmente che il bipolarismo si sia tradotto in bipartitismo. Anzi, la frammentazione partitica è rimasta elevata e questo non solo per la presenza di una arena proporzionale, $\mathrm{ma}$ anche a causa della strategia elettorale adottata da tutti i partiti di formare «cartelli elettorali» basati su accordi di spartizione delle candidature comuni nei collegi determinando una sorta di «proporzionalizzazione del sistema maggioritario» (D'Alimonte 1994, Di Virgilio 1994). Il risultato è stato che gli effetti di questo sistema si sono prodotti a livello di singoli collegi, ma non a livello nazionale. Escludendo le liste minori, sia alla Camera che al Senato troviamo più di 10 partiti/ movimenti (Tabb. 2 e 3 ).

Alla influenza della competizione maggioritaria ha contribuito molto la persistente (ancora per quanto?) divisione dell'elettorato in aree di voto ideologicamente omogenee; fattore questo che ha amplificato gli effetti del voto maggioritario rendendo più forti in termini di seggi quei partiti o quelle coalizioni elettorali che erano già forti in virtù di radici sub-culturali $\mathrm{e}$ organizzative ancora robuste oppure che hanno potuto contare

${ }^{3}$ Questo risultato però è la somma algebrica della sovrarappresentazione del $\mathrm{Pds}$ e di Rc e della sottorappresentazione delle altre liste di sinistra che non hanno superato la soglia del $4 \%$ dei voti. A questo proposito merita sottolineare che la differenza dei risultati tra Camera e Senato, e anche la differenze tra destra e sinistra alla Camera, è in parte influenzata anche dal fatto che i Progressisti hanno ottenuto complessivamente meno seggi proporzionali alla Camera a causa della perdita di quasi l' $8 \%$ dei voti proporzionali per il mancato superamento della soglia del $4 \%$ da parte di Rete, Verdi, Psi e Ad. Sull'effetto che questo fattore ha avuto sulla ripartizione dei seggi proporzionali fra gli schieramenti e all'interno dello schieramento di sinistra si veda Chiaramonte (1994). La conclusione di questo autore è che l'effetto comunque sarebbe stato limitato anche in ragione del fatto che una parte dei seggi persi da Rete, Verdi, Psi e Ad sono andati comunque anche al Pds e Rc. 
TAB. 2. Risultati generali della Camera dei Deputati per partiti e coalizioni

\begin{tabular}{|c|c|c|c|c|c|c|c|c|}
\hline \multirow{2}{*}{ Partiti e coalizioni } & \multicolumn{2}{|c|}{ Voti di lista } & \multicolumn{2}{|c|}{ Seggi proporzionali } & \multicolumn{2}{|c|}{ Seggi maggionitari } & \multicolumn{2}{|c|}{ Seggi totali } \\
\hline & $\mathrm{N}$ & $\%$ & $\mathrm{~N}$ & $\%$ & $\mathrm{~N}$ & $\%$ & $\mathrm{~N}$ & $\%$ \\
\hline Pds & 7.855 .610 & 20,4 & 37 & 23,9 & 72 & 152 & 109 & 173 \\
\hline $\mathrm{Re}$ & 2.334 .029 & 6,0 & 12 & 7,7 & 27 & 5,7 & 39 & 6,2 \\
\hline Verdi & $1.042 .4 \%$ & 2,7 & 0 & 0,0 & 11 & 2,3 & 11 & 1,7 \\
\hline Psi & 841.739 & 2,2 & 0 & 0,0 & 14 & 2,9 & 14 & 2,2 \\
\hline Rete & 718.403 & 1,9 & 0 & 0,0 & 6 & 1,3 & 6 & 1,0 \\
\hline Ad & 452.396 & 1,2 & 0 & 0,0 & 18 & 3,8 & 18 & 2,9 \\
\hline Cs & & & & & 5 & 1,1 & 5 & 0,8 \\
\hline Rs & & & & & 1 & 0,2 & 1 & 0,2 \\
\hline Ind. Sin. & & & & & 10 & 2,1 & 10 & 1,6 \\
\hline Tot. Progressisti & 13.244 .673 & 34,3 & 49 & 31,6 & 164 & 34,5 & 213 & 33,8 \\
\hline Ppi & 4.268 .940 & 11,1 & 29 & 18,7 & 4 & 0,8 & 33 & 5,2 \\
\hline Patto Segni & 1.795 .270 & 4,7 & 13 & 8,4 & 0 & 0,0 & 13 & 2,1 \\
\hline Tot. Patto per l'Italia & 6.064 .210 & 15,7 & 42 & 27,1 & 4 & 0,8 & 46 & 7,3 \\
\hline Forza Italia & 8.119287 & 21,0 & & & & & & \\
\hline Forza Italia & & & 25 & 16,1 & 74 & 15,6 & 99 & 15,7 \\
\hline $\mathrm{Ccd}^{1}$ & & & 7 & 4,5 & 22 & 4,6 & 29 & 4,6 \\
\hline Udc & & & & & 4 & 0,8 & 4 & 0,6 \\
\hline Pld & & & & & 2 & 0,4 & 2 & 0,3 \\
\hline Riformatori & & & & & 6 & 1,3 & 6 & 1,0 \\
\hline An & 5.202 .698 & 13,5 & 22 & 142 & 87 & 183 & 109 & 17,3 \\
\hline Lega Nord & 3.237 .026 & 8,4 & 10 & 6,5 & 107 & 22,5 & 117 & 18,6 \\
\hline $\mathrm{Lp}$ & 1.355 .739 & 3,5 & 0 & 0,0 & 0 & 0,0 & 0 & 0,0 \\
\hline Tot. Podi & 17.914 .750 & 46,4 & 64 & 41,3 & $302^{2}$ & 63,6 & 366 & 58,1 \\
\hline Svp & 231.826 & 0,6 & 0 & 0,0 & 3 & 0,6 & 3 & 0,5 \\
\hline Lista Valle d'Aosta & & & & & 1 & 0,2 & 1 & 0,2 \\
\hline Lega d'Azione Merid. & d. 59.853 & 0,2 & 0 & 0,0 & 1 & 0,2 & 1 & 0,2 \\
\hline Socialdemocrazia & 179.367 & 0,5 & 0 & 0,0 & 0 & 0,0 & 0 & 0,0 \\
\hline Lega Alpina Lumbard & rda 135.954 & 0,4 & 0 & 0,0 & 0 & 0,0 & 0 & 0,0 \\
\hline Verdi-Verdi & 32.815 & 0,1 & 0 & 0,0 & 0 & 0,0 & 0 & 0,0 \\
\hline Altre Leghe & 134.471 & 0,3 & 0 & 0,0 & 0 & 0,0 & 0 & 0,0 \\
\hline Liste autonomiste & 33.425 & 0,1 & 0 & 0,0 & 0 & 0,0 & 0 & 0,0 \\
\hline Altre liste & 565.779 & 1,5 & 0 & 0,0 & 0 & 0,0 & 0 & 0,0 \\
\hline Tot. Aliri & 1373.490 & 3,6 & 0 & 0,0 & 5 & 1,1 & 5 & 0,8 \\
\hline Totale & 8.594 .477 & 100,0 & 155 & 100,0 & 475 & 100,0 & 630 & 100,0 \\
\hline
\end{tabular}

Legenda: Pds: Partito Democratico della Sinistra; Rc: Rifondazione Comunista; Verdi: Federazione dei Verdi; Psi: Partito Socialista Italiano; Rete: Movimento per la democrazia-La Rete; Ad: Alleanza Democratica; Cs: Cristiano-Sociali; Rs: Rinascita Socialista; Ind. Sin.: Indipendenti di Sinistra; Ppi: Partito Popolare Italiano; Ccd: Centro Cristiano Democratico; Udc: Unione di Centro; Pld: Polo Liberal-Democratico; An: Alleanza Nazionale; Lp: Lista Pannella; Svp: Sudtiroler Volkspartei.

Note: vedi p. 636. 
TAB. 3. Risultati generali del Senato per partiti e coalizioni

\begin{tabular}{|c|c|c|c|c|c|c|c|c|}
\hline \multirow{2}{*}{ Partiti e coalizioni } & \multicolumn{2}{|c|}{ Voti } & \multicolumn{2}{|c|}{ Seggi proporzionali } & \multicolumn{2}{|c|}{ Seggi maggioritari } & \multicolumn{2}{|c|}{ Seggi totali } \\
\hline & $\mathrm{N}$ & $\%$ & $\mathrm{~N}$ & $\%$ & $\mathrm{~N}$ & $\%$ & $\mathrm{~N}$ & $\%$ \\
\hline $\begin{array}{l}\text { Pds } \\
\text { RC } \\
\text { Verdi } \\
\text { Psi } \\
\text { Rete } \\
\text { Ad } \\
\text { Cs } \\
\text { Rs } \\
\text { Ind. Sin. }\end{array}$ & & & $\begin{array}{r}14 \\
4 \\
0 \\
1 \\
4 \\
3 \\
0 \\
0 \\
0\end{array}$ & $\begin{array}{r}16,9 \\
4,8 \\
0,0 \\
1,2 \\
4,8 \\
3,6 \\
0,0 \\
0,0 \\
0,0\end{array}$ & $\begin{array}{r}46 \\
14 \\
7 \\
11 \\
2 \\
7 \\
4 \\
1 \\
4\end{array}$ & $\begin{array}{r}19,8 \\
6,0 \\
3,0 \\
4,7 \\
0,9 \\
3,0 \\
1,7 \\
0,4 \\
1,7\end{array}$ & $\begin{array}{r}60 \\
18 \\
7 \\
12 \\
6 \\
10 \\
4 \\
1 \\
4\end{array}$ & $\begin{array}{r}19,0 \\
5,7 \\
2,2 \\
3,8 \\
1,9 \\
3,2 \\
1,3 \\
0,3 \\
1,3\end{array}$ \\
\hline Tot. Progressisti & 10.883 .507 & 32,9 & 26 & 31,3 & 9 & 41,4 & 122 & 38,7 \\
\hline $\begin{array}{l}\text { Ppi } \\
\text { Patto Segni }\end{array}$ & & & $\begin{array}{r}27 \\
1\end{array}$ & $\begin{array}{r}32,5 \\
12\end{array}$ & $\begin{array}{l}3 \\
0\end{array}$ & $\begin{array}{l}1,3 \\
0,0\end{array}$ & $\begin{array}{r}30 \\
1\end{array}$ & $\begin{array}{l}9,5 \\
0,3\end{array}$ \\
\hline Tot. Patto per l'Italia & a 5.518 .615 & 16,7 & 28 & 33,7 & 3 & 1,3 & 31 & 9,8 \\
\hline $\begin{array}{l}\text { Polo delle Libertà } \\
\text { Polo del buon gov. } \\
\text { Forza Italia } \\
\text { Ccd } \\
\text { Udc } \\
\text { Riformatori } \\
\text { An } \\
\text { Lega Nord } \\
\text { Pannella-Riformatori }\end{array}$ & $\begin{array}{r}6.570 .544 \\
4.544 .671 \\
150,326^{1} \\
\\
\\
\\
\\
2.079 .593^{3} \\
\text { i } \quad 767.400\end{array}$ & $\begin{array}{r}19,9 \\
13,7 \\
0,5\end{array}$ & $\begin{array}{r}7 \\
2 \\
0 \\
0 \\
13 \\
5 \\
1\end{array}$ & $\begin{array}{r}8,4 \\
2,4 \\
0,0 \\
0,0 \\
15,7 \\
6,0 \\
1,2\end{array}$ & $\begin{array}{r}25 \\
10 \\
3 \\
1^{2} \\
34 \\
55 \\
0\end{array}$ & $\begin{array}{r}10,8 \\
4,3 \\
1,3 \\
0,4 \\
14,7 \\
23,7 \\
0,0\end{array}$ & $\begin{array}{r}32 \\
12 \\
3 \\
1 \\
47 \\
60 \\
1\end{array}$ & $\begin{array}{r}10,2 \\
3,8 \\
1,0 \\
0,3 \\
14,9 \\
19,0 \\
0,3\end{array}$ \\
\hline Tot. Poli & 14.112 .534 & 42,7 & 284 & 33,7 & 128 & 55,1 & 156 & 49,5 \\
\hline $\begin{array}{l}\text { Lega Alpina Lumbar. } \\
\text { Svp } \\
\text { Lista Magris } \\
\text { Lista Valle d'Aosta } \\
\text { Part. Pensionati } \\
\text { Ps d'Az. } \\
\text { Verdi-Verdi } \\
\text { Socialdemocrazia } \\
\text { Altre Leghe } \\
\text { Liste autonomiste } \\
\text { Altre liste }\end{array}$ & $\begin{array}{r}246.476 \\
217.250 \\
61398 \\
27.493 \\
250.543 \\
88.351 \\
68.068 \\
66.467 \\
341.220 \\
175.684 \\
1.020 .796\end{array}$ & $\begin{array}{l}0,7 \\
0,7 \\
0,2 \\
0,1 \\
0,8 \\
0,3 \\
0,2 \\
0,2 \\
1,0 \\
0,5 \\
3,1\end{array}$ & $\begin{array}{l}1 \\
0 \\
0 \\
0 \\
0 \\
0 \\
0 \\
0 \\
0 \\
0 \\
0\end{array}$ & $\begin{array}{l}1,2 \\
0,0 \\
0,0 \\
0,0 \\
0,0 \\
0,0 \\
0,0 \\
0,0 \\
0,0 \\
0,0 \\
0,0\end{array}$ & $\begin{array}{l}0 \\
3 \\
1 \\
1 \\
0 \\
0 \\
0 \\
0 \\
0 \\
0 \\
0\end{array}$ & $\begin{array}{l}0,0 \\
1,3 \\
0,4 \\
0,4 \\
0,0 \\
0,0 \\
0,0 \\
0,0 \\
0,0 \\
0,0 \\
0,0\end{array}$ & $\begin{array}{l}1 \\
3 \\
1 \\
1 \\
0 \\
0 \\
0 \\
0 \\
0 \\
0 \\
0\end{array}$ & $\begin{array}{l}0,3 \\
1,0 \\
0,3 \\
0,3 \\
0,0 \\
0,0 \\
0,0 \\
0,0 \\
0,0 \\
0,0 \\
0,0\end{array}$ \\
\hline Tot. Altri & 2.563 .746 & 7,8 & 1 & 1,2 & 5 & 2,2 & 6 & 1,9 \\
\hline Totale & 3.078 .402 & 100,0 & 83 & 100,0 & 232 & 100,0 & 315 & 100,0 \\
\hline
\end{tabular}

Legenda: Pds: Partito Democratico della Sinistra; Rc: Rifondazione Comunista; Verdi: Federazione dei Verdi; Psi: Partito Socialista Italiano; Rete: Movimento per la democrazia-La Rete; Ad: Alleanza Democratica; Cs: Cristiano-Sociali; Rs: Rinascita Socialista; Ind. Sin.: Indipendenti di Sinistra; Ppi: Partito Popolare Italiano; Ccd: Centro Cristiano Democratico; Udc: Unione di Centro; An: Alleanza Nazionale; Lp: Lista Pannella; Svp: Südtiroler Volkspartei; Ps d'Az.: Partito Sardo d'Azione.

Note: vedi p. 636. 
su di una affinità ideologica con strati elettorali importanti che hanno perso i precedenti punti di riferimento partitici. $\grave{E}$ così che si spiega almeno in parte il successo clamoroso del Polo delle libertà $(\mathrm{Pl})$ in tutto il Nord e soprattutto nel Nord-Est e quello altrettanto clamoroso dei Progressisti nelle regioni del Centro (Tabb. 4 e 5).

\section{Note tabella 2}

1 I voti del Ccd, presente con una propria lista solo in Molise, sono stati inseriti alla voce «Altre liste»; i 7 seggi proporzionali conseguiti sono stati dunque attribuiti a candidati del Ccd nelle liste di Forza Italia.

${ }^{2}$ Questi seggi sono stati così ottenuti: 164 dal Pl (di cui: Lega Nord 107, Forza Italia 38, Ccd 8, Riformatori 6, Udc 3, Pld 2), 129 dal Pbg (di cui: An 79, Forza Italia 36, Ccd 13, Udc 1), 1 da Forza Italia-Ccd (Mastella) e 8 da An da sola.

Fonti: Elaborazioni degli autori su dati del Ministero dell'Interno e delle segreterie organizzative dei partiti. L'attribuzione delle sigle di partito non tiene conto dei mutamenti intervenuti dopo le elezioni.

\section{Note tabella 3}

${ }^{1}$ Sono $\mathrm{i}$ voti conseguiti in Abruzzo dal gruppo Forza Italia-Ccd, i candidati del quale si presentavano in contrapposizione a quelli di Alleanza Nazionale.

2 Si tratta di Stanzani, candidato del Polo delle Libertà in Veneto.

3 Sono i voti che An ha ottenuto presentando candidati al di fuori del Polo del buon governo (in Piemonte, Lombardia, Trentino Alto Adige, Veneto, Friuli Venezia Giulia, Liguria, Emilia Romagna, Toscana, Marche, Umbria e Abruzzo).

${ }_{4}^{4}$ Questi seggi sono stati così ottenuti: 8 dal Pl (di cui: Lega Nord 5 e Forza Italia 3), 10 dal Pbg (di cui: An 5, Forza Italia 3, Ccd 2), 8 da An da sola, 1 da Forza ItaliaCcd e 1 da Lista Pannella-Riformatori (Scoppelliti).

5 Di cui 74 vinti dal Polo delle Libertà e 54 dal Polo del buon governo.

Fonti: Elaborazioni degli autori su dati del Ministero dell'Interno e delle segreterie organizzative dei partiti. L'attribuzione delle sigle di partito non tiene conto dei mutamenti intervenuti dopo le elezioni. 
TAB. 4. I seggi maggioritari per forza politica e circoscrizioni elettorali (Camera)

\begin{tabular}{|c|c|c|c|c|c|c|c|c|c|c|}
\hline \multirow{2}{*}{ Circoscrizioni } & \multirow{2}{*}{ Seggi } & \multicolumn{9}{|c|}{ Forze politiche } \\
\hline & & Prog & Patto & $\mathrm{Pl}$ & $\mathrm{Pbg}$ & $\mathrm{Fi}$ & An & Sup & Uv & Lam \\
\hline Valle d'Aosta & 1 & & & & & & & & 1 & \\
\hline Piemonte 1 & 19 & 5 & & 14 & & & & & & \\
\hline Piemonte 2 & 17 & & & 17 & & & & & & \\
\hline Lombardia 1 & 31 & & & 31 & & & & & & \\
\hline Lombardia 2 & 32 & & & 32 & & & & & & \\
\hline Lombardia 3 & 11 & 1 & & 10 & & & & & & \\
\hline Trentino A.A. & 8 & & & 4 & & & 1 & 3 & & \\
\hline Veneto 1 & 22 & & & 22 & & & & & & \\
\hline Veneto 2 & 15 & 1 & & 14 & & & & & & \\
\hline Friuli V.G. & 10 & & & 10 & & & & & & \\
\hline Liguria & 14 & 7 & & 7 & & & & & & \\
\hline Emilia - Rom. & 32 & 29 & & 3 & & & & & & \\
\hline Toscana & 29 & 29 & & & & & & & & \\
\hline Umbria & 7 & 7 & & & & & & & & \\
\hline Marche & 12 & 12 & & & & & & & & \\
\hline Lazio 1 & 32 & 3 & & & 29 & & & & & \\
\hline Lazio 2 & 11 & & & & 11 & & & & & \\
\hline Abruzzo & 11 & 10 & & & & & 1 & & & \\
\hline Molise & 3 & 1 & & & 2 & & & & & \\
\hline Campania 1 & 25 & 15 & & & 10 & & & & & \\
\hline Campania 2 & 22 & 12 & 3 & & & $1^{1}$ & 6 & & & \\
\hline Puglia & 34 & 10 & & & 23 & & & & & 1 \\
\hline Basilicata & 5 & 4 & & & 1 & & & & & \\
\hline Calabria & 17 & 10 & & & 7 & & & & & \\
\hline Sicilia 1 & 20 & 4 & & & 16 & & & & & \\
\hline Sicilia 2 & 21 & & & & 21 & & & & & \\
\hline Sardegna & 14 & 4 & 1 & & 9 & & & & & \\
\hline Italia & 475 & 164 & 4 & 164 & 129 & 0 & 8 & 3 & 1 & 1 \\
\hline
\end{tabular}

Legenda: Prog: Progressisti; Patto: Patto per l'Italia; Pl: Polo delle Libertà; Pbg: Polo del buon governo; Fi: Forza Italia; An: Alleanza Nazionale; Svp: Südtiroler Volkspartei; Uv: Union Valdotaine; Lam: Lega d'Azione Meridionale.

1 È il seggio vinto da Mastella del Ccd presentatosi collegato solo a Forza Italia ma con i simboli di Fi, Ccd, Udc e Pld.

Escludendo l'Emilia-Romagna, i Progressisti hanno ottenuto alla Camera solo 14 seggi maggioritari su 180 al Nord, di cui due soli ad est del Ticino! Per converso, Lega Nord (Ln), Forza Italia (Fi) e Alleanza Nazionale (An) hanno ottenuto invece solo tre seggi su 80 nella tradizionale «zona rossa». Al 
TAB. 5. I seggi maggioritari per forza politica e circoscrizioni regionali (Senato)

\begin{tabular}{|c|c|c|c|c|c|c|c|c|}
\hline \multirow{2}{*}{ Circoscrizioni } & \multirow{2}{*}{ Seggi } & \multicolumn{6}{|c|}{ Forze politiche } & \multirow[b]{2}{*}{ Magris } \\
\hline & & Prog & Patto & $\mathrm{PI}$ & $\mathrm{Pbg}$ & Svp & Uv & \\
\hline Valle d'Aosta & 1 & & & & & & 1 & \\
\hline Piemonte & 17 & 5 & & 12 & & & & \\
\hline Lombardia & 35 & & & 35 & & & & \\
\hline Trentino A.A. & 6 & & & 3 & & 3 & & \\
\hline Veneto & 17 & & & 17 & & & & \\
\hline Friuli V.G. & 5 & & & 4 & & & & 1 \\
\hline Liguria & 6 & 4 & & 2 & & & & \\
\hline Emilia - Rom. & 15 & 14 & & 1 & & & & \\
\hline Toscana & 14 & 14 & & & & & & \\
\hline Umbria & 5 & 5 & & & & & & \\
\hline Marche & 6 & 6 & & & & & & \\
\hline Lazio & 21 & 5 & & & 16 & & & \\
\hline Abruzzo & 5 & 5 & & & & & & \\
\hline Molise & 2 & 2 & & & & & & \\
\hline Campania & 22 & 13 & 2 & & 7 & & & \\
\hline Puglia & 16 & 7 & & & 9 & & & \\
\hline Basilicata & 5 & 4 & & & 1 & & & \\
\hline Calabria & 8 & 7 & & & 1 & & & \\
\hline Sicilia & 20 & 3 & & & 17 & & & \\
\hline Sardegna & 6 & 2 & 1 & & 3 & & & \\
\hline Italia & 232 & 9 & 3 & 74 & 54 & 3 & 1 & 1 \\
\hline
\end{tabular}

Legenda: Prog: Progressisti; Patto: Patto per l'Italia; Pl: Polo delle Libertà; Pbg: Polo del buon governo; Svp: Südtiroler Volkspartei; Uv: Union Valdotaine; Magris: Gruppo Magris.

Senato, il quadro non cambia sostanzialmente: i Progressisti hanno fatto leggermente meglio al Nord in termini percentuali, il polo di destra ha fatto addirittura peggio al Centro (un solo senatore!).

Questi dati parlano da soli. Mentre la tabella 1 ha messo in luce la differenza tra esito maggioritario ed esito proporzionale e soprattutto la differenza tra Camera e Senato, le tabelle 4 e 5 e ancor meglio la tabella 6 rivelano un'altra caratteristica importante di queste elezioni: la suddivisione del Paese in tre aree di cui due assolutamente non competitive (Nord e Centro) e una invece fortemente competitiva (Sud) ${ }^{4}$.

${ }^{4}$ Nella individuazione di queste aree abbiamo semplicemente fatto riferimento ai 
TAB. 6. Ripartizione dei seggi maggioritari (\%) per forza politica e per area (Camera e Senato)

\begin{tabular}{lrrrrrr}
\hline & \multicolumn{5}{c}{ Forze politiche } & \\
\cline { 2 - 4 } Aree & Prog. & Patto & Poli & Altri & Totale & Seggi \\
\hline Camera & & & & & & \\
Nord & 7,7 & 0,0 & 90,0 & 2,2 & 100,0 & 180 \\
Centro & 96,3 & 0,0 & 3,8 & 0,0 & 100,0 & 80 \\
Sud & 34,0 & 1,9 & 63,7 & 0,5 & 100,0 & 215 \\
Totale & 34,5 & 0,8 & 63,6 & 1,1 & 100,0 & 475 \\
& & & & & & \\
Senato & & & & & & \\
Nord & 10,3 & 0,0 & 83,9 & 5,7 & 100,0 & 87 \\
Centro & 97,5 & 0,0 & 2,5 & 0,0 & 100,0 & 40 \\
Sud & 45,7 & 2,9 & 51,4 & 0,0 & 100,0 & 105 \\
Totale & 41,4 & 1,2 & 55,2 & 2,2 & 100,0 & 232 \\
\hline
\end{tabular}

Legenda: Area Nord: Nord esclusa Emilia Romagna; Area Centro: Emilia Romagna-Toscana-Umbria-Marche; Area Sud: regioni restanti, comprese le isole.

Certamente questo è l'effetto del sistema maggioritario utilizzato, $\mathrm{ma}$ in modo particolare del suo interagire con altri fattori quali l'insediamento sub-nazionale e le tradizioni storicoculturali che hanno prevalso (almeno in questa fase) su fattori tipicamente locali e personali. Il «voto personale» (cioè, il voto al candidato), che è uno dei possibili comportamenti di voto indotti dal sistema maggioritario, c'è stato probabilmente solo al Sud $e$ anche lì forse in misura limitata. In altre parole, $i$ candidati hanno contato poco. Questo spiega almeno in parte l'as-

risultati di queste elezioni e non ad un criterio geografico o a criteri geo-politici di cui è ricca la letteratura. Ciò premesso, nel Nord abbiamo compreso tutte le regioni settentrionali meno l'Emilia-Romagna. Il Centro è la zona di tradizionale insediamento storico della sinistra (Emilia-Romagna, Toscana, Marche, Umbria). Il Sud comprende tutte le altre regioni. All'interno di queste tre zone esistono certamente differenze importanti. Al Nord, in alcune zone del Piemonte e della Liguria, la sinistra va meglio che nel resto di questa zona. Al Centro, in alcuni collegi dell'Emilia e delle Marche la competizione è più equilibrata. Al Sud, la Sicilia in particolare si stacca dalle altre regioni. In un quadro di insieme però le differenze tra le zone hanno assunto in queste elezioni una rilevanza maggiore delle differenze intra-area, anche per effetto del sistema maggioritario. Per un'analisi di queste elezioni in chiave di mappe geo-politiche si veda Natale (1994) e Diamanti (1994). 
senza di varianza tra collegi e la presenza di una sola area elettorale competitiva.

Sulla base di queste considerazioni è facile comprendere le difficoltà di una analisi che si concentra sulla competizione elettorale tra candidati. L'ancora forte peso dei suddetti fattori ha determinato l'appiattimento della varianza all'interno di determinate e politicamente caratterizzate aree geo-politiche. Alla lunga (ma nemmeno tanto, probabilmente), se la logica del sistema maggioritario prevarrà ci dobbiamo aspettare una diminuzione della varianza tra aree e un aumento della varianza all'interno di ogni singola area.

Nell'attesa però che il sistema maggioritario esplichi tutti i suoi effetti dobbiamo accontentarci di una sola area dove varianza e livello di competizione sono stati elevati: il Sud. Questa area è stata molto importante ai fini del risultato complessivo. Infatti, nonostante il successo della coalizione di destra, questo successo avrebbe potuto essere ancora più ampio se i Progressisti non avessero ottenuto nel Sud un numero di seggi maggioritari inaspettatamente (e relativamente) elevato. $\grave{E}$ il risultato della competizione maggioritaria nel Sud che ha impedito allo schieramento di destra di ottenere la maggioranza assoluta dei seggi totali al Senato e sfiorare addirittura i due terzi dei seggi alla Camera.

Perché si sono prodotte queste differenze nell'arena maggioritaria tra Camera e Senato, e tra Nord/Centro da una parte e Sud dall'altra? A queste domande cercheremo di rispondere in questo saggio attraverso l'analisi di quattro dimensioni della competizione elettorale nei collegi: 1) la competitività degli scontri; 2) il ruolo della frammentazione; 3 ) i modelli di competizione; 4) la coesione elettorale degli schieramenti. Queste quattro dimensioni di analisi non sono indipendenti l'una dall'altra, bensì si intersecano tra loro (soprattutto le prime tre) e sono inoltre influenzate in maniera sensibile dalla fortemente diseguale distribuzione territoriale del voto per le maggiori formazioni. Pur con questo caveat, procederemo in questo articolo cercando da una parte di evidenziare i collegamenti tra loro e dall'altra di trattare all'interno di ciascuna di esse il problema delle differenze territoriali e di quelle tra Camera e Senato.

Ciò premesso, quali sono gli obiettivi che ci proponiamo in questo saggio? In primo luogo, descrivere il più accuratamente possibile i risultati maggioritari. In secondo luogo, spiegare non tanto perché lo schieramento di destra abbia vinto, ma descrive- 
re come abbia vinto. Procederemo pertanto attraverso un'analisi interna ai dati che non tiene conto tanto delle variabili ambientali e storico-culturali che hanno influenzato la formazione delle preferenze elettorali quanto dei meccanismi del sistema elettorale e della struttura della competizione così come si è configurata nel corso della campagna elettorale. In sostanza, ci interessa vedere come le preferenze elettorali combinandosi con i meccanismi del sistema elettorale hanno determinato l'esito di queste elezioni. $\grave{E}$ in questo modo che cercheremo di individuare le origini elettorali del Parlamento divisos.

\section{La competitività elettorale}

In un contesto di elezioni con sistema maggioritario-uninominale, è semplice definire chi sono i candidati competitivi: sono quelli che vincono ovvero quelli che, pur perdendo, arrivano comunque a ridosso del vincitore. La distanza tra i primi e i secondi arrivati è quindi l'indicatore più importante che useremo per analizzare il livello di competitività degli scontri nei collegi. Fa però una grande differenza quale sia la soglia di vittoria, vale a dire la percentuale minima di voti necessaria a vincere il seggio in ciascun collegio. Va da sé infatti che un conto è vincere con il $50 \%$ dei voti e un altro è vincere con il $30 \%$. Anche se è possibile parlare di elezioni e di candidature competitive nell'uno e nell'altro caso. Per questo motivo, all'analisi della competitività in senso proprio, premettiamo una analisi dettagliata delle medie di vittoria, cioè delle percentuali di voto che si sono rivelate sufficienti a vincere il seggio.

Il primo modo di studiare il fenomeno è quello di vedere sinteticamente cosa è successo alla Camera e al Senato nelle tre zone in cui abbiamo diviso il Paese (Tab. 7).

$5 \mathrm{Ci}$ corre l'obbligo a questo punto di sottolineare che in questo lavoro non teniamo conto di un possibile, e spesso citato, fattore di spiegazione delle differenze Camera-Senato: il voto giovanile. L'ipotesi che sia questo fattore il vero responsabile del peggior andamento della sinistra alla Camera rispetto al Senato è stata avanzata da più parti (soprattutto - a dire il vero - in commenti giornalistici) sia facendo riferimento alla differenza dei voti tra Camera e Senato sia a dati di sondaggio. Sulla validità del primo metodo abbiamo serissimi dubbi. I dati di sondaggio invece sono contraddittori. La nostra opinione è che questo fattore abbia giocato un ruolo tutto sommato modesto. Una spia è rappresentata dal fatto che $\mathrm{i}$ candidati progressisti ottengono complessivamente una percentuale di voti validi praticamente identica alla Camera $(32,8 \%)$ e al Senato $(32,9)$. Per di più le liste progressiste ottengono alla Camera il $34,3 \%$ dei voti. 
TAB. 7. Percentuale media di voto dei candidati uninominali vincenti (Camera e Senato)

\begin{tabular}{lcccc}
\hline & $\begin{array}{c}\text { Nord } \\
\%\end{array}$ & $\begin{array}{c}\text { Centro } \\
\%\end{array}$ & $\begin{array}{c}\text { Sud } \\
\%\end{array}$ & $\begin{array}{c}\text { Tutti } \\
\%\end{array}$ \\
\hline Camera & $50,00(180)$ & $48,38(80)$ & $41,32(215)$ & $45,80(475)$ \\
Senato & $39,55(87)$ & $45,20(40)$ & $35,65(105)$ & $38,76(232)$ \\
Tutti & $46,60(267)$ & $47,31(120)$ & $39,47(340)$ & $43,49(707)$ \\
\hline
\end{tabular}

In parentesi il numero di seggi uninominali.

Nette sono le differenze tra Camera e Senato e tra zone geografiche. In tutte le zone si vince alla Camera con una percentuale di voti superiore rispetto al Senato. E a livello nazionale la differenza è del $7 \%$. Perché? Quali elementi nella struttura della competizione sono responsabili di queste differenze? I deputati del Nord e del Centro in media hanno vinto il seggio con il $50 \%$ dei voti o quasi. In un sistema bipartitico questo sarebbe ovviamente un fatto normale, ma in un sistema come il nostro caratterizzato - come vedremo meglio tra poco - da una elevata frammentazione, il dato ha un rilievo particolare. Tanto più che al Nord i senatori ottengono il seggio con una percentuale media di voti di poco più del $39 \%$ : una differenza di quasi 11 punti! Mentre al Centro la differenza c'è, ma è abbastanza marginale.

Anche le differenze territoriali sono significative. Alla Camera, la diminuzione della soglia di vittoria è costante dal Nord al Sud. Al Senato invece no: il dato del Centro è nettamente superiore rispetto a quello delle altre due zone. Altra osservazione interessante: $\mathrm{i}$ senatori al Nord ottengono mediamente meno voti dei deputati al Sud. La tabella 8 dà un quadro della situazione che, seppur più disaggregato, non modifica sostanzialmente la lettura che ne abbiamo già fatto, ma che ci consente di cogliere meglio anche le variazioni intra-area soprattutto rispetto alla differenza Camera-Senato.

Questa differenza è una costante che vale per tutte le circoscrizioni/regioni. A parte il caso anomalo della Campania 2, la soglia di vittoria al Senato è sempre inferiore a quella della $\mathrm{Ca}$ mera. Ma il dato più utile che possiamo ricavare da questa tabella riguarda la variabilità intra-area. Da questo punto di vista, 
Tав. 8. Percentuale media di voti dei candidati uninominali vincenti nelle singole circoscrizioni (Camera e Senato)

\begin{tabular}{|c|c|c|c|c|c|}
\hline \multicolumn{3}{|c|}{ Camera } & \multicolumn{3}{|c|}{ Senato } \\
\hline Circoscrizioni & $\begin{array}{c}\mathrm{N} \text { collegi } \\
\text { uninominali }\end{array}$ & $\begin{array}{l}\text { Media \% voti } \\
\text { del vincente }\end{array}$ & Circoscrizioni & $\begin{array}{c}\mathrm{N} \text { collegi } \\
\text { uninominali }\end{array}$ & $\begin{array}{c}\text { Media \% voti } \\
\text { del vincente }\end{array}$ \\
\hline Valle d'Aosta & 1 & 54,1 & Valle d'Aosta & 1 & 35,3 \\
\hline Piemonte 1 & 19 & 41,2 & Piemonte & 17 & 35,7 \\
\hline Piemonte 2 & 17 & 49,0 & & & \\
\hline Lombardia 1 & 31 & 53,0 & Lombardia & 35 & 41,4 \\
\hline Lombardia 2 & 32 & 57,9 & & & \\
\hline Lombardia 3 & 11 & 52,1 & & & \\
\hline Trentino A.A. & 8 & 50,7 & Trentino A.A. & 6 & 43,2 \\
\hline Veneto 1 & 22 & 48,3 & Veneto & 17 & 38,4 \\
\hline Veneto 2 & 15 & 47,4 & & & \\
\hline Friuli V.G. & 10 & 45,7 & Friuli V.G. & 5 & 39,3 \\
\hline Liguria & 14 & 44,9 & Liguria & 6 & 40,0 \\
\hline Emilia Rom. & 32 & 49,7 & Emilia Rom. & 15 & 46,6 \\
\hline Toscana & 29 & 49,5 & Toscana & 14 & 45,7 \\
\hline Umbria & 7 & 48,3 & Umbria & 5 & 463 \\
\hline Marche & 12 & 42,4 & Marche & 6 & 39,3 \\
\hline Lazio 1 & 32 & 49,1 & Lazio & 21 & 39,4 \\
\hline Lazio 2 & 11 & 48,9 & & & \\
\hline Abruzzo & 11 & 33,5 & Abruzzo & 5 & 32,9 \\
\hline Molise & 3 & 33,7 & Molise & 2 & 31,3 \\
\hline Campania 1 & 25 & 43,1 & Campania & 22 & 362 \\
\hline Campania 2 & 22 & 28,9 & & & \\
\hline Puglia & 34 & 39,2 & Puglia & 16 & 32,6 \\
\hline Basilicata & 5 & 40,8 & Basilicata & 5 & 31,1 \\
\hline Calabria & 17 & 38,3 & Calabria & 8 & 34,5 \\
\hline Sicilia 1 & 20 & 44,7 & Sicilia & 20 & 37,5 \\
\hline Sicilia 2 & 21 & 47,5 & & & \\
\hline Sardegna & 14 & 36,8 & Sardegna & 6 & 32,0 \\
\hline
\end{tabular}

Nord e Sud sono simili. Alla Camera-Nord si va da una soglia media minima del $41,2 \%$ nel Piemonte 1 ad una massima del $57,9 \%$ della Lombardia 2: una differenza di 16,7 punti. Al SudCamera si va dal minimo (anomalo) della Campania $2(28,9 \%)$ al massimo del 49,1\% del Lazio 1: la differenza è di 20,2 punti. Se escludiamo i due casi anomali della Campania 2 e Abruzzo e prendiamo come minimo significativo il Molise $(33,5 \%)$, la differenza è pur sempre del $15,6 \%$. Un dato simile a quello della Camera-Nord, ma - e questo è il punto - molto diverso da quello del Centro dove la differenza è del 7,3\%. È il Centro

${ }^{6}$ Nelle Marche, in Abruzzo e nella Campania 2, Forza Italia e Alleanza Nazionale erano divise, presentando ciascuna propri candidati. 
quindi la zona più omogenea da questo punto di vista, quella dove la soglia di vittoria varia meno.

$\mathrm{Al}$ Senato la variabilità intra-area è minore rispetto alla $\mathrm{Ca}$ mera e si colloca in tutte le aree intorno all' $8 \%$ circa. Mentre non esiste tra livello Camera e livello Senato una differenza significativa nel Centro, al Nord e al Sud la variabilità intra-area praticamente si dimezza rispetto alla Camera.

Ulteriori informazioni sui livelli di vittoria per area si possono ricavare dalla tabella 9. Qui i vincenti sono divisi per classi di voto. Questa classificazione comincia a dirci qualcosa sui livelli di competitività quanto meno ai due estremi della scala. Alla Camera, in quasi un terzo dei collegi $(32,5 \%)$ i vincitori hanno avuto la maggioranza assoluta dei voti. Di questi più della metà sono al Nord (90/154). Tra l'altro è qui che troviamo addirittura 20 candidati con più del $60 \%$ dei voti. Al Senato invece la maggioranza assoluta è stata ottenuta solo nel $6,9 \%$ dei collegi, e di questi 11 su 16 sono al Centro e solo 3 al Nord.

Se prendiamo poi le ultime due classi vediamo che alla $\mathrm{Ca}$ mera solo il $12,4 \%$ dei collegi $(59 / 475)$ sono stati vinti con meno del $35 \%$ dei voti e di questi la stragrande maggioranza sono al Sud (52/59) e solo 4 al Nord. Al Senato (anche qui ultime due classi) aumenta notevolmente la percentuale di collegi che possiamo cominciare a chiamare competitivi - il $31,9 \%$ del totale - e aumenta anche la percentuale di quelli che si trovano al Nord (19/74). Il quadro che emerge è sufficientemente chiaro: il livello di competitività misurato in base alla percentuale di collegi dove si vince con soglia di vittoria bassa (meno del $35 \%$ ) è decisamente più elevato al Senato rispetto alla Camera e più elevato al Sud rispetto al Nord e al Centro. Ma anche al Nord il numero dei collegi potenzialmente marginali è più elevato al Senato.

Prima di passare però a questo tipo di analisi centrata sulla distinzione tra collegi sicuri e collegi marginali, occorre completare l'esame della soglia di vittoria introducendo la variabile «schieramento di appartenenza del candidato vincente». In altre parole, chi vince con quale soglia? La risposta è nella tabella 10.

Dalla tabella 10 ricaviamo queste informazioni:

1. resta la differenza sistematica tra Camera e Senato per tutti i gruppi con una sola eccezione significativa (anche se limitata a pochi casi) rappresentata dai Pattisti che vincono con medie maggiori al Senato rispetto alla Camera; 


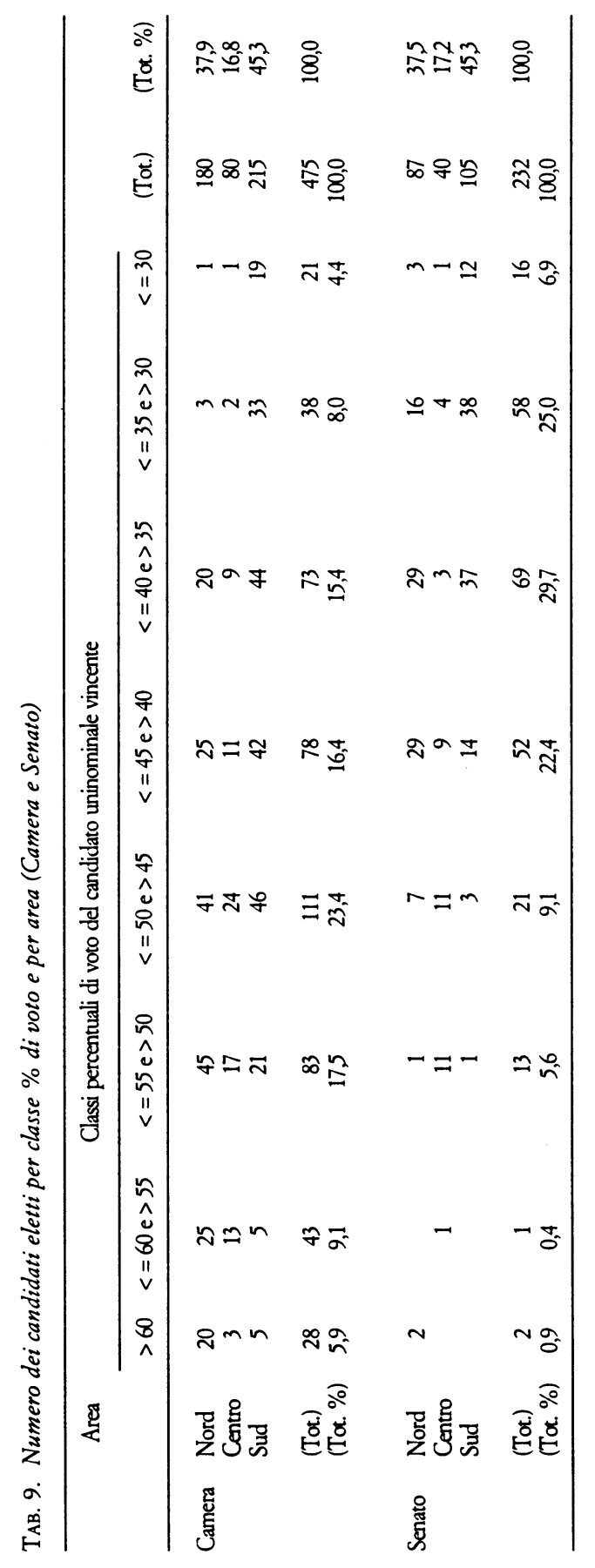


TAB. 10. Percentuale media di voto dei candidati uninominali vincenti a seconda dello schieramento di appartenenza (Camera e Senato)

\begin{tabular}{lrrrrr}
\hline & \multicolumn{2}{c}{ Camera } & & \multicolumn{2}{c}{ Senato } \\
\cline { 2 - 3 } \cline { 5 - 6 } Schieramento & N seggi vinti & $\%$ media di voto & & N seggi vinti & \% media di voto \\
\hline Progressisti & 164 & 43,4 & & 97 & 39,4 \\
Patto per l'Italia & 4 & 30,5 & & 3 & 35,5 \\
Polo delle libertà & 164 & 50,0 & & 74 & 39,2 \\
Polo buon governo & 129 & 44,5 & & 54 & 36,2 \\
Forza Italia + altri & 1 & 25,2 & & & \\
Alleanza Naz. & 8 & 27,8 & & & 52,8 \\
Altri & 5 & 65,0 & & 4 & 38,8 \\
Tutti & 475 & 45,8 & & 232 & \\
\hline
\end{tabular}

2. i Progressisti vincono con medie inferiori alla media generale alla Camera e superiore alla media generale al Senato;

3. Polo delle libertà e Polo del buon governo presentano nette differenze tra le due Camere: nel caso del primo Polo la differenza è addirittura superiore al $10 \%$; nel caso del secondo è quasi l' $8 \%$; in entrambi i casi è decisamente superiore a quella dei Progressisti che è di circa il $4 \%$;

4. i candidati del Patto e quelli di Forza Italia e Alleanza nazionale che si presentano da soli vincono con percentuali di voto molto basse.

La tabella 11 serve ad approfondire il quadro consentendo di studiare le vittorie maggioritarie non solo in termini di livello medio, ma anche nella loro distribuzione per classi di livello. Risalta ancora più con questi dati il diverso rendimento dei due Poli tra Camera e Senato. Un solo senatore del Polo delle libertà è eletto con più del $50 \%$ dei voti mentre sono ben 85 i deputati dello stesso polo che superano la soglia di maggioranza. Lo stesso accade (anche se in misura meno accentuata) con il Polo del buon governo: 28 deputati sopra il $50 \%$ contro un solo senatore.

Per i Progressisti lo squilibrio è minore a conferma della maggiore omogeneità del Centro (l'area dove vincono di più): 37 deputati a maggioranza assoluta contro 12 senatori. Ma i 12 senatori progressisti rappresentano di gran lunga la maggioranza dei senatori eletti con più del $50 \%$ dei voti $(12 / 16)$.

Dall'altra parte della scala il rapporto tra i due Poli e i Progressisti si inverte alla Camera. Sono i Progressisti a vincere il 


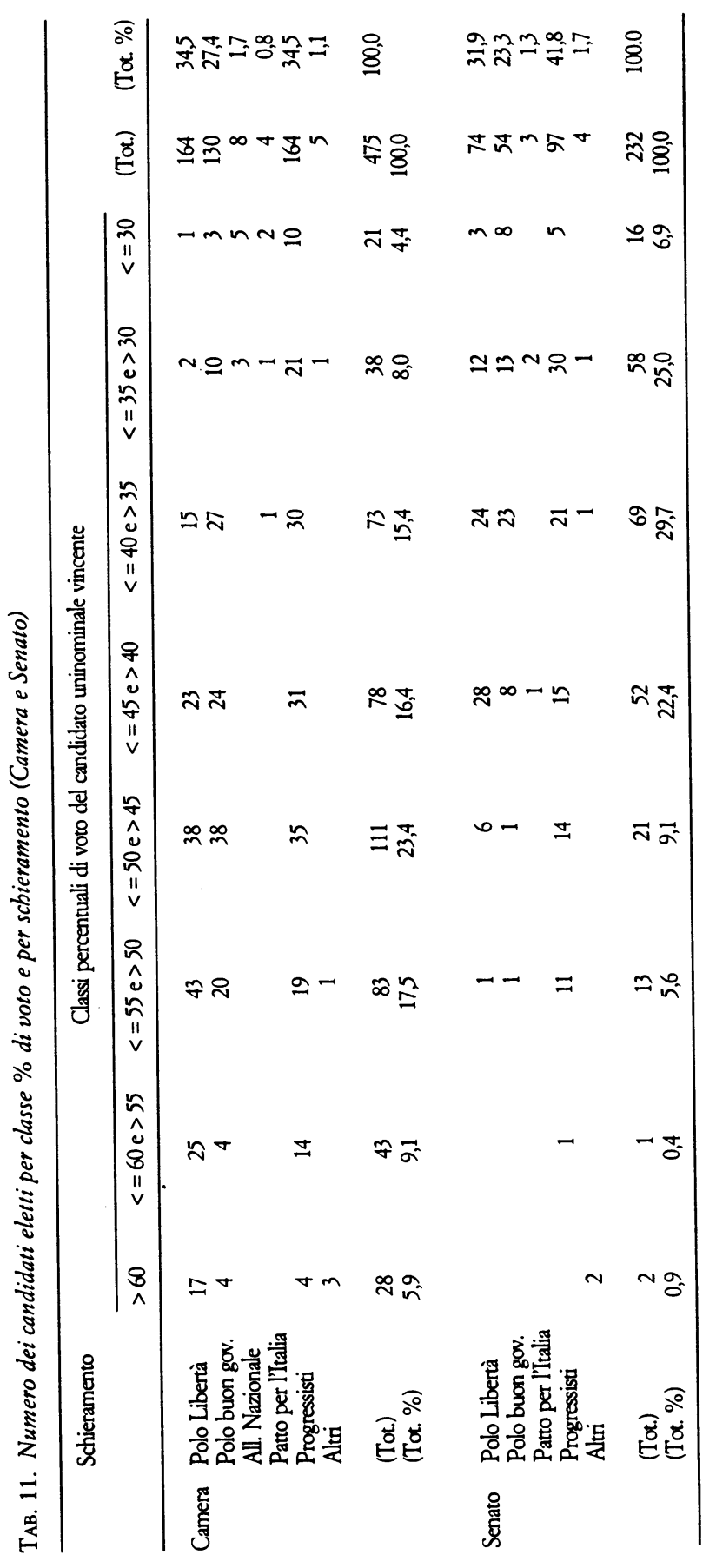


maggior numero di seggi con meno del 35\% (31/59) contro 16 seggi su 59 per i due Poli. Al Senato invece la situazione è più equilibrata. I Progressisti ne vincono 35 su 74 e i due Poli 36 su 74.

In conclusione, con questa tabella fissiamo tre dati importanti: 1) la maggioranza dei seggi vinti con medie basse (sotto il $35 \%$ ) si trova al Senato; 2) la maggioranza di questi seggi alla Camera è vinta dai Progressisti; 3) al Senato invece i Progressisti e i Poli si dividono quasi perfettamente questo tipo di seggi. Quest'ultimo punto è particolarmente interessante perché è alla Camera che la destra era più divisa. Eppure, è al Senato che fa più fatica a vincere. Avremo modo di tornare su questo paradosso.

Fin qui abbiamo studiato le soglie, ora passiamo a studiare le differenze di voti tra primo e secondo candidato in ciascun collegio. È questa in realtà la dimensione-chiave della competitività elettorale, quella che ci consente di definire il tipo di scontro e eventualmente il tipo di collegio. In prima approssimazione definiremo come competitivi (o marginali) quegli scontri (e quei collegi) in cui la distanza in termini di voti tra i primi due candidati è uguale o inferiore all' $8 \%$ dei voti, indipendentemente dalla percentuale di voti ottenuta dal vincente. Nello stesso senso parleremo anche di collegi marginali e di marginalità elettorale. Va da sé ovviamente che la soglia dell' $8 \%$ scelta per operazionalizzare questi concetti è del tutto convenzionale, ma a noi sembra indicativa del fenomeno che vogliamo studiare. Aggiungiamo poi che percentuali di poco inferiori o superiori non sposterebbero comunque i risultati della nostra analisi.

Un numero elevato di collegi competitivi sta ad indicare tendenzialmente un elevato grado di incertezza dell'esito elettorale. Occorre aggiungere però che la competitività (e quindi l'incertezza) dipende anche dalla volatilità elettorale, cioè dalla dimensione dell'elettorato disponibile a spostare il proprio voto dall'uno all'altro candidato. In teoria quindi una distanza di voti minima tra primo e secondo potrebbe anche coesistere con una assoluta mancanza di competitività. Perché questo si verifichi in pratica occorre però che vengano soddisfatte condizioni molto restrittive concernenti l'inelasticità del voto.

Più interessante invece è il caso opposto. Una grande distanza tra primo e secondo potrebbe coesistere con un forte grado di competitività elettorale in situazioni - quale per esempio quella italiana attuale - di forte destrutturazione del merca- 
TAB. 12. Frequenze delle classi di differenza di voto (\%) tra primi e secondi candidati di collegio per area (Camera e Senato)

\begin{tabular}{|c|c|c|c|c|c|c|c|c|c|c|}
\hline \multirow[t]{2}{*}{. } & \multirow[t]{2}{*}{ Differenza $1^{\circ} \cdot 2^{\circ}$} & \multirow[t]{2}{*}{ Cam. + Sen. } & \multicolumn{4}{|c|}{ Camera } & \multicolumn{4}{|c|}{ Senato } \\
\hline & & & Nord & Centro & Sud & Italia & Nord & Centro & Sud & Italia \\
\hline collegi & $0-4 \%$ & 110 & 9 & 5 & 50 & 64 & 12 & & 34 & 46 \\
\hline \multirow[t]{3}{*}{ marginali } & $4-8 \%$ & 118 & 13 & 2 & 59 & 74 & 6 & 1 & 37 & 44 \\
\hline & $8-12 \%$ & 89 & 14 & 7 & 38 & 59 & 13 & 3 & 14 & 30 \\
\hline & $12 \cdot 16 \%$ & 82 & 18 & 10 & 29 & 57 & 13 & 3 & 9 & 25 \\
\hline collegi & $16-20 \%$ & 53 & 11 & 7 & 12 & 30 & 14 & 2 & 7 & 23 \\
\hline \multirow[t]{3}{*}{ sicuri } & $20-24 \%$ & 66 & 22 & 5 & 14 & 41 & 16 & 8 & 1 & 25 \\
\hline & $24-28 \%$ & 63 & 28 & 15 & 4 & 47 & 5 & 8 & 3 & 16 \\
\hline & $28 \cdot 32 \%$ & 40 & 16 & 11 & 4 & 31 & 4 & 5 & & 9 \\
\hline \multirow{6}{*}{$\begin{array}{l}\text { collegi } \\
\text { fortezza }\end{array}$} & $32-36 \%$ & 29 & 17 & 5 & 1 & 23 & 2 & 4 & & 6 \\
\hline & $36-40 \%$ & 23 & 10 & 8 & 1 & 19 & & 4 & & 4 \\
\hline & $40-44 \%$ & 18 & 10 & 3 & 3 & 16 & & 2 & & 2 \\
\hline & $44-48 \%$ & 9 & 7 & 2 & & 9 & & & & 0 \\
\hline & $>48 \%$ & 7 & 5 & & & 5 & 2 & & & 2 \\
\hline & Totali & 707 & 180 & 80 & 215 & 475 & 87 & 40 & 105 & 232 \\
\hline
\end{tabular}

to elettorale e quindi di forte volatilità, dove per forte si intende sia il grado di disponibilità che il numero di elettori disponibili a cambiare voto tra una elezione e l'altra.

Per questi motivi occorre quindi grande cautela nell'uso di concetti quali marginalità elettorale, collegi competitivi (o marginali). Tanto più che nel nostro caso abbiamo a disposizione una sola elezione ed è dunque impossibile fare raffronti intertemporali sulla propensione dei singoli elettorati di collegio a modificare gli orientamenti di voto. Più forte sarebbe il nostro argomento se potessimo contare su una serie di elezioni maggioritarie. In tal caso, la variabile tempo ci consentirebbe di arrivare a conclusioni più fondate sui livelli di competitività elettorale nei collegi. Ciononostante, e con i caveat di cui sopra, procederemo a classificare i collegi della Camera e del Senato usando questa variabile che a noi sembra importante per valutare, anche in prospettiva, l'esito delle elezioni italiane di marzo.

Nella tabella 12 abbiamo operazionalizzato questa variabile sulla base di 13 classi, ciascuna delle quali (eccetto l'ultima) rappresenta valori di quattro punti percentuali. I collegi marginali sono quelli che rientrano nelle prime due classi. Gli altri sono i collegi sicuri. All'interno di questa categoria abbiamo identificato anche il sotto-insieme dei collegi-fortezza, quelli 
TAB. 13. Differenza media di voto (\%) tra primi e secondi candidati di collegio in base allo schieramento vincente e per area (Camera e Senato)

\begin{tabular}{|c|c|c|c|c|c|c|c|c|c|}
\hline \multirow[t]{2}{*}{ Schieramento } & \multirow[t]{2}{*}{ Cam.+Sen. } & \multicolumn{4}{|c|}{ Camera } & \multicolumn{4}{|c|}{ Senato } \\
\hline & & Nord & Centro & Sud & Italia & Nord & Centro & Sud & Italia \\
\hline $\mathrm{Fi}+\mathrm{Ln}+$ Altri & $22,0(238)$ & $25,0(161)$ & $5,5(3)$ & & $24,6(164)$ & $16,3(73)$ & $8,5(1)$ & & $16,2(74)$ \\
\hline$F_{i}+A n+$ Altri & $10,6(183)$ & & & $11,7(129)$ & $11,7(129)$ & & & $7,9(54)$ & $7,9(54)$ \\
\hline $\mathrm{Fi}+$ Altri & $5,0(1)$ & & & $5,0(1)$ & $5,0(1)$ & & & & \\
\hline An & $5,3(8)$ & $32(1)$ & & $5,6(7)$ & $5,3(8)$ & & & & \\
\hline Patto & $5,7(7)$ & & & $5,8(4)$ & $5,8(4)$ & & & $5,5(3)$ & $5,5(3)$ \\
\hline Progressisti & $15,3(261)$ & $9,1(14)$ & $24,1(77)$ & $8,0(73)$ & $15,6(164)$ & $7,9(10)$ & 25,7 (39) & $7,1(48)$ & $14,7(97)$ \\
\hline Altri & $42,0(9)$ & $55,4(4)$ & & $0,6(1)$ & $44,4(5)$ & $39,0(4)$ & & & \\
\hline Totali & $16,5(707)$ & $24,4(180)$ & $23,3(80)$ & $10,0(215)$ & $17,7(475)$ & $16,4(87)$ & $25,3(40)$ & $7,5(105)$ & $13,9(232)$ \\
\hline
\end{tabular}

Tra parentesi il numero dei casi.

dove la distanza primo-secondo è superiore a 32 punti percentuali. I collegi marginali occupano una posizione importante nella interpretazione del risultato di queste elezioni, ma prima è opportuno fare una analisi più generale della competitività tenendo conto di tutti i collegi. La domanda da cui partiamo è questa: con quali distacchi medi hanno vinto i propri seggi i candidati dei diversi schieramenti nelle diverse aree del Paese? La risposta è nella tabella 13 .

Se definiamo la competitività elettorale in funzione della differenza di voti tra primo e secondo arrivato, i dati della tabella 13 non fanno che rafforzare l'affermazione che abbiamo già fatto sulla divisione del Paese in tre aree di cui una competitiva e due no. Al Nord-Camera, il Polo delle libertà non solo vince la grande maggioranza dei seggi (161/180) contro i 14 dei Progressisti, ma i suoi candidati ottengono in media il $25 \%$ dei voti in più del secondo arrivato (che nella grandissima maggioranza dei casi è il candidato progressista). Una distanza abissale. La stessa che caratterizza le vittorie dei candidati progressisti rispetto ai loro avversari nel Centro.

In queste due zone la competitività elettorale è praticamente inesistente. Come suggeriscono questi dati, e come vedremo più approfonditamente tra poco, i seggi marginali sono pochissimi. Pur tuttavia, esiste una differenza non trascurabile tra Camera e Senato; una differenza che pur non cambiando il quadro complessivo, ci fornisce una conferma ulteriore della maggiore omogeneità elettorale del Centro rispetto al Nord. Infatti, mentre i Progressisti nel Centro fanno meglio al Senato rispetto alla $\mathrm{Ca}$ - 
mera (il 25,7\% contro il 24\%), per il Polo delle libertà al Nord non è così. Anzi, il distacco medio tra candidati del polo e i loro avversari diminuisce significativamente (dal $25 \%$ al 16,3\%), pur restando ben al di sopra della nostra soglia di competitività.

L'unica zona veramente competitiva è il Sud, sia alla Camera che al Senato. Non solo, come abbiamo già visto, i Progressisti vincono (soprattutto al Senato) un numero di seggi considerevole (48 su 105) dimostrandosi così più competitivi che al Nord. Oltre a ciò, la distanza media al Senato tra i candidati eletti del Polo delle libertà e i loro avversari (per la maggior parte progressisti) è solo del $8 \%$. Qui gli scontri sono stati veramente competitivi come dimostra anche la distanza media $(7,1 \%)$ dei vincitori progressisti. Anche alla Camera-Sud, i distacchi sono molto inferiori rispetto alla Camera-Nord, sia quando vincono i 73 candidati del Polo $(11,7 \%)$ che quando vincono i 129 candidati progressisti ( $8 \%$ ). In conclusione, l'unica zona dove potevamo aspettarci un numero significativo di collegi marginali è il Sud, e così è.

I collegi marginali, secondo la nostra definizione, sono quelli in cui la differenza massima di voti tra il candidato vincente e il secondo arrivato non supera l'8\%. Perché questo tipo di collegi è tanto importante da giustificare una trattazione separata? La ragione è una, ma può essere scomposta in due punti.

Primo, un numero elevato di collegi marginali sta ad indicare un grado elevato di competitività elettorale e quindi una elevata incertezza riguardante l'esito complessivo delle elezioni. Elezioni con molti collegi marginali lasciano la porta aperta alla possibilità di grossi mutamenti elettorali nelle elezioni successive, mutamenti amplificati dal sistema maggioritario a un turno.

Secondo, un'elevata percentuale relativa di collegi marginali vinti da un dato partito (rispetto al totale dei seggi ottenuti) è un indice di vulnerabilità elettorale. Partiti che vincono molti seggi al margine sono potenzialmente più soggetti di altri a perdite consistenti di seggi alle elezioni successive in conseguenza di perdite di voti anche modeste.

Queste relazioni dipendono naturalmente dalla definizione empirica di marginalità. Questa definizione, per quanto convenzionale, può essere soggetta a variazioni temporali. Una differenza di voti superiore all' $8 \%$ può rappresentare un margine di sicurezza in periodi di bassa volatilità elettorale, mentre una differenza del $20 \%$ potrebbe non essere sufficiente a garantire la rielezione al candidato in carica se la volatilità elettorale fosse 
TAB. 14. I collegi marginali per area (Camera e Senato)

\begin{tabular}{|c|c|c|c|c|c|c|c|c|}
\hline \multirow[b]{2}{*}{ Area } & \multicolumn{4}{|c|}{ Camera } & \multicolumn{4}{|c|}{ Senato } \\
\hline & $\begin{array}{l}\mathrm{N} \text { seggi } \\
\text { maggionitari }\end{array}$ & $\begin{array}{c}N \text { seggi } \\
\text { marginali }\end{array}$ & $\begin{array}{l}\text { Seggi marg. } \\
\% \text { su area }\end{array}$ & $\begin{array}{l}\text { Seggi marg. } \\
\% \text { su totale }\end{array}$ & $\begin{array}{c}\mathrm{N} \text { seggi } \\
\text { maggioritari }\end{array}$ & $\begin{array}{c}N \text { seggi } \\
\text { marginali }\end{array}$ & $\begin{array}{l}\text { Seggi marg. } \\
\% \text { su area }\end{array}$ & $\begin{array}{l}\text { Seggi marg } \\
\text { \% su totale }\end{array}$ \\
\hline Nord & 180 & 22 & 12,2 & 15,9 & 87 & 18 & 20,7 & 20,0 \\
\hline Centro & 80 & 7 & 8,8 & 5,1 & 40 & 1 & 2,5 & 1,1 \\
\hline Sud & 215 & 109 & 50,7 & 79,0 & 105 & 71 & 67,6 & 78,9 \\
\hline Italia & 475 & 138 & 29,1 & 100,0 & 232 & 90 & 38,8 & 100,0 \\
\hline
\end{tabular}

elevata. Ora, dato che i tassi di volatilità elettorale mutano nel tempo, così cambia la definizione empirica di marginalità.

Ciò premesso, quanti sono, quali sono e dove sono questi collegi? Chi ne sono i vincitori? Dalla tabella 13 sappiamo già che questi collegi sono 138 alla Camera e 90 al Senato: rispettivamente il $29 \%$ e il $38,8 \%$ del totale dei seggi maggioritari di ciascuna camera. Sono pochi, sono molti? È difficile dirlo senza un controllo comparato. Prescindendo da questo tipo di valutazioni, possiamo comunque dire che il Senato è stato decisamente più competitivo della Camera. Una differenza di quasi 10 punti non è trascurabile, tanto più che una quota dei collegi marginali della Camera è certamente dovuta al divorzio tra Forza Italia e Alleanza Nazionale in alcune circoscrizioni; un fattore questo che non ha giocato al Senato.

La tabella 14 ci dà la distribuzione territoriale di questi collegi. La grande maggioranza sono al Sud, come ci aspettavamo. Sia alla Camera che al Senato, rappresentano più della metà di tutti i collegi di quella zona (rispettivamente il $50,7 \%$ e il $67,6 \%$ ) e addirittura in tutte e due i casi una percentuale praticamente identica $(79 \%$ e $78,9 \%)$ di tutti i collegi competitivi nel Paese. Questo dato è una ulteriore conferma che il Sud è stato l'unica zona veramente competitiva. Il Centro, invece, è quella meno competitiva. Al Senato addirittura un unico collegio competitivo e alla Camera solo sette.

In conclusione, questi dati ci dicono che le elezioni si sono «giocate» al Sud e soprattutto al Senato nel Sud. Infatti, i 71 seggi marginali in questa camera, in questa zona, rappresentano non solo, come abbiamo visto il $78,9 \%$ di tutti i seggi marginali del Senato, ma soprattutto sono il $30,6 \%$ di tutti i seggi mag- 
TAB. 15. Seggi marginali e schieramenti elettorali per area (Camera e Senato)

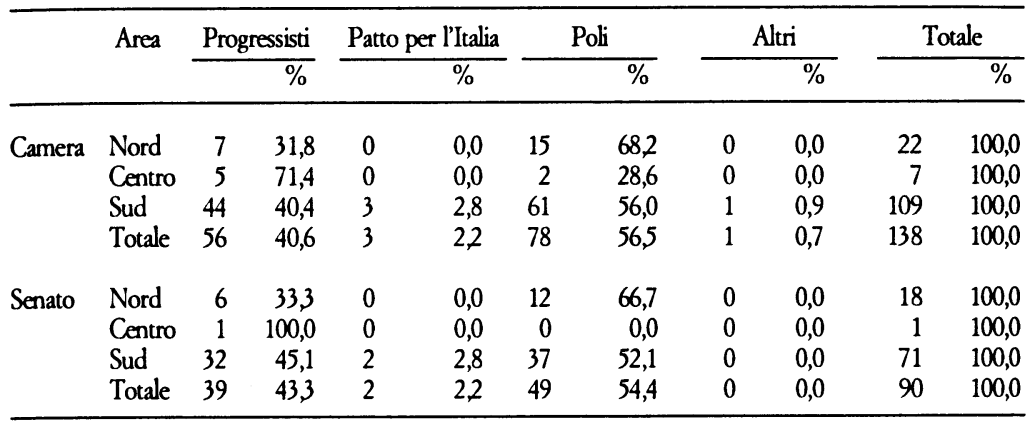

gioritari senatoriali. Uno spostamento anche di pochi voti in questa zona avrebbe modificato significativamente l'esito delle elezioni in questa camera. Resta a questo punto da chiedersi chi ha vinto i seggi marginali (Tab. 15).

Lo schieramento di destra ha vinto la maggioranza di questi seggi (56,5\% alla Camera e 54,4\% al Senato). Ma i Progressisti ottengono un risultato positivo che gli consente di riequilibrare soprattutto al Senato la propria posizione parlamentare $(40,6 \%$ alla Camera e $43,3 \%$ al Senato). Infatti, sia alla Camera che al Senato, la percentuale dei seggi marginali vinti è superiore a quella del totale dei seggi maggioritari mentre per i Poli è vero il contrario (cfr. Tabb. 15 e 1).

Questo dato assume un significato ancora maggiore se confrontiamo la percentuale dei seggi marginali vinti dai due schieramenti principali rispetto al totale dei loro seggi maggioritari (Tab. 16). I Progressisti «dipendono» da questi seggi più dei Poli. La differenza è sensibile soprattutto alla Camera.

Ma sono soprattutto i dati del Senato al Sud a fornirci una chiave di spiegazione dell'esito di queste elezioni (Tab. 15). I Progressisti hanno vinto in totale 96 seggi maggioritari. Di questi 48 sono nel Sud. Di questi 48, 32 (cioè i due terzi) sono seggi marginali. Complessivamente, i Progressisti hanno vinto il $45,1 \%$ dei seggi marginali al Sud rispetto al 52,1\% dello schieramento di destra. E un risultato senz'altro positivo che testimonia della competitività della sinistra in questa zona. Ma è anche un risultato che nasconde un elemento di potenziale debolezza. I collegi marginali sono collegi potenzialmente vulnerabili. Coeteris paribus, un esito meno favorevole per la sinistra in termini di voti in questi collegi si tradurrebbe in una netta per- 
TAB. 16. Il peso dei seggi marginali sul totale dei seggi maggioritari per Poli (Pl, Pbg e loro varianti) e Progressisti (Camera e Senato)

\begin{tabular}{lccccccc}
\hline & \multicolumn{3}{c}{ Camera } & & \multicolumn{3}{c}{ Senato } \\
\cline { 2 - 3 } Schieramenti & $\begin{array}{c}\text { Seggi } \\
\text { marginali } \\
\text { A }\end{array}$ & $\begin{array}{c}\text { Seggi } \\
\text { maggionitari } \\
\text { B }\end{array}$ & $\%$ A/B & & $\begin{array}{c}\text { Seggi } \\
\text { marginali } \\
\text { A }\end{array}$ & $\begin{array}{c}\text { Seggi } \\
\text { maggionitari } \\
\text { B }\end{array}$ & $\%$ A/B \\
\hline Poli & 78 & 302 & 25,8 & & 49 & 128 & 38,3 \\
Progressisti & 56 & 164 & 34,1 & & 39 & 96 & 40,6 \\
\hline
\end{tabular}

dita di seggi e conseguentemente in un equilibrio parlamentare sostanzialmente diverso dall'attuale. Naturalmente è possibile sostenere anche il contrario: basterebbero pochi voti in più per incrementare significativamente il bottino di seggi. Quindi anche la destra è vulnerabile. Quale è l'esito più probabile? Difficile dirlo ora con sicurezza. Ma il fatto che la sinistra abbia vinto nella maggior parte di questi collegi con percentuali di voto relativamente basse davanti ad una destra spesso divisa e frammentata sembra indicare una sua maggiore vulnerabilità tendenziale. Ma su questa previsione avremo modo di tornare.

A questo punto abbiamo completato l'analisi descrittiva della competitività elettorale. Ma quali fattori possono aiutarci a comprendere le distribuzioni evidenziate in questa sezione? In particolare, quali sono le ragioni per cui i livelli di competitività sono così differenziati territorialmente, tra Camera e Senato e per schieramento politico? E soprattutto, perché la sinistra è andata meglio al Senato in generale e al Sud in particolare? Ricordando al lettore che in questo articolo limitiamo la nostra analisi ai fattori relativi alla struttura della competizione (trascurando quanto attiene alla forza relativa dei partiti) cercheremo di dare una prima risposta nel prosieguo di questo saggio concentrando la nostra attenzione su quattro fattori esplicativi: 1) la frammentazione dell'offerta; 2) la concentrazione del voto; 3) i modelli di competizione; 4) la coesione elettorale degli schieramenti politici.

\section{La frammentazione dell'offerta: il numero di candidati}

L'adozione del sistema maggioritario ad un turno non si è tradotta immediatamente in una drastica semplificazione del- 
l'offerta. Al contrario, rispetto alle elezioni precedenti il nuovo sistema sembra aver incentivato la presentazione di candidature, la maggior parte delle quali assolutamente non competitive, anche se - come vedremo - non irrilevanti dal punto di vista del risultato finale.

I dati della tabella 17 sono per diversi aspetti sorprendenti. La frammentazione è decisamente più elevata al Senato rispetto alla Camera. Il numero medio di candidati per collegio al Senato è di 6,3, mentre alla Camera è di 4,5. In 44 collegi al Senato troviamo ben 9 candidati, alla Camera solo in 2. Al Senato il $66,8 \%$ dei collegi ha più di 5 candidati, alla Camera solo il $13,9 \%$. Al Senato la frammentazione è maggiore al Nord rispetto al Sud, alla Camera il contrario. Perché queste differenze? In particolare, perché una differenza così netta tra Camera e Senato? Il fenomeno non è casuale, ma dipende dagli incentivi offerti dal nuovo sistema elettorale. Al momento della presentazione delle candidature un numero consistente di candidati ha preferito il Senato alla Camera. Il Senato infatti presenta innegabili vantaggi per candidati «minori», soprattutto per quelli legati a partiti-movimenti con una base locale-regionale. Ma vediamo meglio.

Per ogni candidato potenziale la scelta del dove presentarsi è influenzata da tre diversi fattori (che costituiscono la struttura degli incentivi di ogni sistema elettorale): 1) gli adempimenti necessari alla presentazione della candidatura (firme, collegamenti, ecc.); 2) la formula per l'attribuzione dei seggi; 3) i mec-

TAB. 17. Distribuzione degli scontri per numero di candidati in competizione e per area (Camera e Senato)

\begin{tabular}{|c|c|c|c|c|c|c|c|c|c|}
\hline \multirow[t]{2}{*}{$N$ cand. } & \multirow[t]{2}{*}{ Cam.+Sen. } & \multicolumn{4}{|c|}{ Camera } & \multicolumn{4}{|c|}{ Senato } \\
\hline & & Nord & Centro & Sud & $\overline{\text { Italia }}$ & Nord & Centro & Sud & $\overline{\text { Italia }}$ \\
\hline 2 & 5 & 1 & & 4 & 5 & & & & \\
\hline 3 & 56 & 2 & 10 & 35 & 47 & & 5 & 4 & 9 \\
\hline 4 & 233 & 106 & 43 & 59 & 208 & 3 & 6 & 16 & 25 \\
\hline 5 & 192 & 59 & 23 & 67 & 149 & 13 & & 30 & 43 \\
\hline 6 & 112 & 12 & 3 & 35 & 50 & 3 & 24 & 35 & 62 \\
\hline 7 & 44 & & 1 & 8 & 9 & 13 & 5 & 17 & 35 \\
\hline 8 & 16 & & & 5 & 5 & 8 & & 3 & 11 \\
\hline 9 & 46 & & & 2 & 2 & 44 & & & 44 \\
\hline 10 & 3 & & & & 0 & 3 & & & 3 \\
\hline Totali & 707 & 180 & 80 & 215 & 475 & 87 & 40 & 105 & 232 \\
\hline
\end{tabular}


canismi del finanziamento pubblico. Nel caso italiano, questi fattori erano così configurati.

Primo, solo al Senato era possibile presentarsi come «candidati singoli» senza quindi alcun collegamento con partiti o gruppi. Ciò comporta l'esclusione dal riparto proporzionale. Alla Camera invece il collegamento con una lista concorrente al riparto proporzionale è necessario indipendentemente dalla volontà del singolo candidato di concorrere all'assegnazione dei seggi proporzionali. Questa differenza tra Camera e Senato comporta un maggior onere organizzativo per i candidati della Camera che tra l'altro devono raccogliere oltre alle firme per la candidatura nel collegio le firme per la presentazione della lista nella circoscrizione.

Secondo, la formula per l'attribuzione dei seggi proporzionali al Senato è più favorevole ai partiti locali-regionali. Alla Camera infatti occorre superare la soglia del $4 \%$ dei voti a livello nazionale per poter accedere alla ripartizione proporzionale. Al Senato invece la soglia non è determinata a priori per legge, ma risulta dalla applicazione a livello regionale del metodo $\mathrm{d}^{\prime}$ Hondt $^{7}$. Per un movimento-partito a base regionale, questa soglia di fatto è sicuramente e relativamente più facile da superare di quella della Camera. Tant'è che la Lega alpina lombarda è riuscita ad ottenere un seggio proporzionale in Lombardia.

Terzo, per accedere al finanziamento pubblico al Senato è sufficiente per un candidato singolo aver ottenuto il 15\% dei voti nel collegio e per un gruppo di candidati aver eletto un candidato in un collegio o aver ottenuto almeno il 5\% dei voti validi nella Regione. Anche in questo caso alla Camera i requisiti sono più onerosi: il $4 \%$ dei voti a livello nazionale.

Questa soglia diventa il 3\% se il partito in questione riesce ad eleggere un candidato in un collegio uninominale.

La somma di questi vantaggi (e soprattutto il secondo) costituisce a nostro avviso una spiegazione forte dei dati che abbiamo presentato sulla frammentazione al Senato ${ }^{8}$. Naturalmen-

7 In realtà, il livello della soglia è influenzato anche da altri fattori. Cfr. D'Alimonte e Chiaramonte (1993). Sul come la soglia ha effettivamente funzionato in queste elezioni si veda Chiaramonte (1994).

${ }^{8}$ Una spiegazione diversa è offerta da Agosta $(1994,24-25)$ il quale sostiene invece che la minore frammentazione dell'offerta alla Camera sia dovuta alla disponibilità della seconda scheda. La sua ipotesi è che la possibilità offerta ai partiti minori di presentarsi in lista (nel proporzionale) senza dover presentarsi anche nei collegi ha favorito la riduzione del numero delle candidature in questa sede, «proteggendo» in un certo 


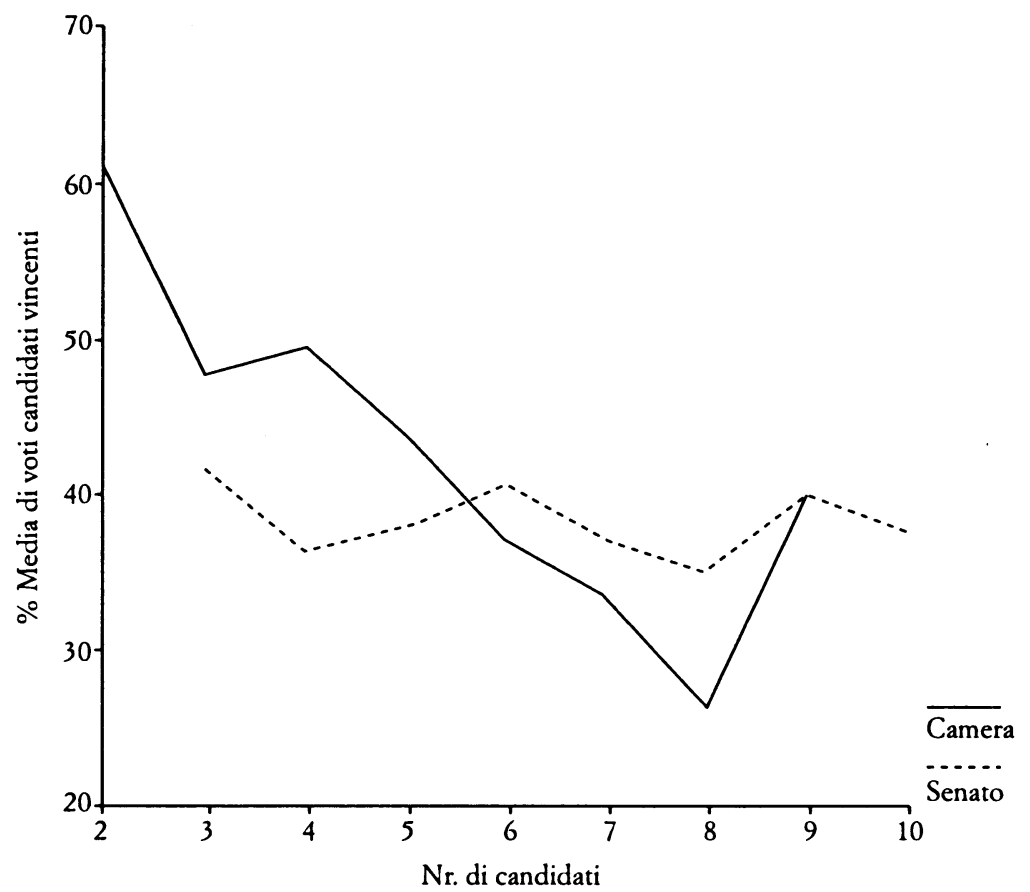

FIG. 1. \% media di voti ai candidati vincenti per numero di candidati in competizione (Camera e Senato).

te non spiega perché il numero medio di candidati al Senato al Nord è di 7,8 (con punte del 9,1 in Lombardia e dell'8,7 in Piemonte) e di 5,5 al Sud. Questa seconda spiegazione va cercata in variabili ambientali che interagiscono con la struttura degli incentivi offerta dal sistema elettorale.

Spiegare perché il Senato è più frammentato della Camera è utile, $\mathrm{ma}$ in questa sede il nostro scopo principale è un altro: a noi interessa soprattutto sapere se e in che misura la variabile «frammentazione dell'offerta» influenza il risultato elettorale. Il

senso la competizione maggioritaria. Questa ipotesi però deve fare i conti con l'esistenza di una soglia alla Camera del $4 \%$ a livello nazionale che costituisce un forte disincentivo proprio per i partiti minori e i candidati e partiti locali. In realtà, a noi sembra, per le ragioni qui esposte, che la decisione di non presentarsi alla Camera e presentarsi invece al Senato è stata influenzata dalla connotazione più regionalista del sistema elettorale del Senato. 
Senato è più competitivo perché è più frammentato? La sinistra vince di più al Senato perché il Senato è più frammentato? A queste domande cercheremo di rispondere partendo dall'analisi del rapporto tra numero di candidati per collegio e i due indicatori di competitività da noi utilizzati: soglia di vittoria e distanza tra i primi due candidati. Alla Camera esiste una relazione significativa negativa tra frammentazione e soglia. La soglia diminuisce quando aumenta il numero dei candidati. Al Senato invece non esiste rapporto tra queste due variabili (Fig. 1).

Se prendiamo poi la distanza tra i primi due ( $\mathrm{Tab} .18$ ), vediamo facilmente che il numero dei candidati non è in alcun modo correlato con questa variabile né alla Camera né al Senato. Su 707 seggi complessivi, quelli con 9 o 10 candidati hanno distanze medie tra i primi due maggiori di quelli con un numero di candidati minore. Solo alla Camera vi è un segno di diminuzione della distanza (e quindi nei nostri termini di aumento della competitività) all'aumentare della frammentazione. Ma è appunto solo un segno, troppo poco per sostenere che ci sia un qualche rapporto considerando anche il basso numero di casi di scontri con più di 6 candidati. Al Senato poi non vi è proprio nessun segno. Anzi, gli scontri più competitivi (a minor distanza) si trovano nel gruppo dei 4 , ma anche degli 8 candidati.

A prima vista quindi sembrerebbe che frammentazione e competitività non siano collegate. Resta il fatto però che la frammentazione al Senato è più elevata che alla Camera, che soglia di vittoria e distanza primo-secondo al Senato sono più basse, che la sinistra vince di più al Senato. Come si possono riconciliare questi dati? Si può affermare che i progressisti vincono di più al Senato perché il Senato è più frammentato? Se fosse così, dovremmo trovare una correlazione positiva tra vittorie progressiste e frammentazione. Ma non è così. Non solo non esiste alcuna correlazione significativa né alla Camera né al Senato a livello nazionale, ma anche al Sud le cose non cambiano. I Progressisti vincono di più in questa zona, ma non perché ci sono qui più candidati che altrove.

In conclusione, il numero dei candidati per collegio non spiega, ma questa variabile coglie solo un aspetto della frammentazione, quella che abbiamo definito come frammentazione dell'offerta. Ai fini del risultato finale, però, il dato che conta è la risposta degli elettori, vale a dire quanti voti sono finiti ai candidati minori. Questo secondo, e più decisivo aspetto della frammentazione, è quello che definiamo come frammentazione 
TAB. 18. Numero di candidati in competizione per collegio e livello medio della differenza tra primo e secondo piazzato

\begin{tabular}{|c|c|c|c|c|c|c|}
\hline \multirow[b]{2}{*}{$\underset{\text { candidati }}{\mathrm{N}}$} & \multicolumn{2}{|c|}{ Camera } & \multicolumn{2}{|c|}{ Senato } & \multicolumn{2}{|c|}{ Tutti } \\
\hline & $\begin{array}{c}\text { Differenza } \% \\
\text { tra } 1^{\circ} \mathrm{e} 2^{\circ}\end{array}$ & $\begin{array}{c}\mathrm{N} \\
\text { casi }\end{array}$ & $\begin{array}{c}\text { Differenza } \% \\
\text { tra } 1^{\circ} \mathrm{e} 2^{\circ}\end{array}$ & $\underset{\text { casi }}{\mathrm{N}}$ & $\begin{array}{c}\text { Differenza \% } \\
\text { tra } 1^{\circ} \text { e } 2^{\circ}\end{array}$ & $\begin{array}{c}\mathrm{N} \\
\text { casi }\end{array}$ \\
\hline 2 & 24,3 & 5 & & 0 & 24,3 & 5 \\
\hline 3 & 13,5 & 47 & 15,1 & 9 & 13,8 & 56 \\
\hline 4 & 22,1 & 208 & 9,7 & 25 & 20,7 & 233 \\
\hline 5 & 163 & 149 & 11,9 & 43 & 153 & 192 \\
\hline 6 & 10,9 & 50 & 15,7 & 62 & 13,6 & 112 \\
\hline 7 & 5,8 & 9 & 13,3 & 35 & 11,8 & 44 \\
\hline 8 & 53 & 5 & 10,7 & 11 & 9,0 & 16 \\
\hline 9 & 8,1 & 2 & 16,3 & 44 & 15,9 & 46 \\
\hline 10 & & 0 & 18,1 & 3 & 18,1 & 3 \\
\hline Totali & 17,7 & 475 & 13,9 & 232 & 16,5 & 707 \\
\hline
\end{tabular}

del voto o della domanda. È la capacità dei candidati minori di raccogliere quote significative di consenso che può influenzare l'esito della competizione tra i candidati maggiori.

La frammentazione della domanda: la concentrazione-dispersione del voto

Molti candidati non fanno necessariamente un sistema competitivo. Nella sezione precedente abbiamo visto al contrario che i collegi più frammentati sono al Senato-Nord, dove il Polo delle libertà ha vinto con relativa facilità la grande maggioranza dei seggi. Il numero di candidati non sembra aver influenzato significativamente il risultato elettorale. Tuttavia per l'analisi della frammentazione non possiamo fermarci a questa variabile. Ma dobbiamo tener conto anche della distribuzione dei voti tra i candidati e soprattutto della capacità di quelli minori di sottrarre voti ai candidati più competitivi. Un numero elevato di candidati può coesistere con un'alta concentrazione del voto sui candidati più importanti e con un elevato livello di competitività, ma potrebbe anche essere il contrario. La frammentazione, misurata in base al numero di candidati per collegio, è solo un indicatore di disponibilità dell'offerta, non della domanda.

Insomma, esiste una «frammentazione che conta» perché 
sottrae voti alla competizione tra i primi due candidati che hanno possibilità di successo e una frammentazione che non conta perché non produce questo effetto. Ma come studiare «la frammentazione che conta»?

In questo saggio procederemo partendo dalla nozione di voto marginale, definito come la differenza tra il totale dei voti validi e il voto ottenuto dai primi due candidati. Il voto marginale, in altre parole, è il complemento dell'indice di concentrazione del voto sui primi due candidati: maggiore la concentrazione del voto, minore il voto marginale. Il criterio sottostante in questo caso è che la competizione elettorale che conta è quella tra i primi due candidati. I terzi e i quarti candidati possono disturbare, ma non competere. L'assunzione implicita è che tutto o quasi il voto marginale, in un sistema maggioritario ad un turno, sia voto potenzialmente mobilitabile a favore dei primi due candidati a mano a mano che il sistema si consolida e che gli elettori apprendono le nuove regole del gioco.

La nozione di voto marginale non distingue però tra candidati minori. Questa distinzione invece può rivelarsi utile nel caso italiano, dato il livello relativamente elevato della frammentazione dell'offerta. Per questo motivo, accanto al voto marginale prenderemo in esame due diversi tipi di voto ai candidati minori: il voto residuale e il voto disperso. Entrambi sono sotto-insiemi del voto marginale.

Il voto residuale è la differenza tra il totale dei voti validi e la somma dei voti ottenuti dai primi quattro candidati. Perché quattro? Nella maggior parte dei collegi, accanto ai candidati dei tre schieramenti nazionali $(\mathrm{Pl}$ o $\mathrm{Pbg}$, Patto e Progressisti) troviamo un quarto candidato con un profilo politico tale da non poter essere considerato un candidato minore (vedi i candidati di An al Nord o quelli della Lista Pannella).

Il voto disperso è il voto dato a candidati periferici, non collegati a modelli di competizione nazionali. Più precisamente, è il voto dato a candidati che in ciascun collegio: $a$ ) hanno ottenuto meno del $4 \%$ dei voti validi, e $b$ ) non facevano parte di liste nazionali; e $c$ ) non erano collegati a liste che abbiano ottenuto più del $4 \%$ dei voti validi nello stesso collegio. Questi criteri di irrilevanza vanno naturalmente intesi in senso relativo. Il voto dato ad un candidato minore è un voto sicuramente irrilevante ai fini della elezione di quel candidato, ma può non essere affatto irrilevante ai fini della determinazione dell'esito della competizione tra i candidati maggiori. In ogni caso il peso di 
TAB. 19. Il voto marginale (\% sul totale dei voti validi ai candidati) per area (Camera $e$ Senato)

\begin{tabular}{lcccc}
\hline & \multicolumn{4}{c}{ Area } \\
\cline { 2 - 5 } & $\begin{array}{c}\text { Nord } \\
\%\end{array}$ & $\begin{array}{c}\text { Centro } \\
\%\end{array}$ & $\begin{array}{c}\text { Sud } \\
\%\end{array}$ & $\begin{array}{c}\text { Italia } \\
\%\end{array}$ \\
\hline Camera & 24,4 & 26,6 & 27,4 & 26,1 \\
Senato & 37,3 & 34,9 & 36,1 & 36,4 \\
Cam. + Sen. & 28,6 & 29,3 & 30,3 & 29,5 \\
\hline
\end{tabular}

questo voto è una questione empirica. E questo giustifica la decisione di farne una categoria di analisi separata.

La tabella $19 \mathrm{fa}$ il quadro sul voto marginale. Tre sono i punti da sottolineare: 1) il livello elevato di questo tipo di voto e quindi la bassa concentrazione del voto sui primi due candidati; 2) la differenza significativa tra Camera e Senato (oltre 10 punti percentuali) e 3) l'assenza di variazioni territoriali rilevanti. Soprattutto al Senato, i primi due candidati raccolgono poco. Gli altri candidati riescono a conquistare in media più di un terzo dei voti. Il Senato dunque non solo è più competitivo, ma lo è ad un livello più basso di concentrazione del voto. Sembrerebbe quindi che la maggior consistenza del voto marginale, oltre ad essere correlata positivamente con la frammentazione delle candidature, favorisca la competitività.

$\mathrm{Ma}$ esiste una correlazione tra chi vince e voto marginale? La risposta è sostanzialmente negativa (Tab. 20). Che vincano i Progressisti o che vincano i candidati dei Poli, il voto marginale non cambia. Solo alla Camera-Sud esiste tra i due schieramenti una differenza significativa, ma questa è probabilmente spiegata dalla divisione della destra in alcune circoscrizioni meridionali che si traduce in una minore concentrazione del voto sui primi due candidati.

In conclusione, il voto marginale non ci dice molto. Del resto, come abbiamo visto, la concentrazione sui primi due può essere solo un indicatore della forza locale di un solo schieramento e quindi non avere alcun rilievo per la competizione tra $\mathrm{i}$ primi due, anzi indicare il contrario. Questo è uno dei motivi per ricorrere ad un altro indicatore che colga meglio l'idea del «restringimento dell'area elettorale di competizione», l'area cioè sottratta allo scontro tra i concorrenti principali, quelli collegati 
TAB. 20. Il voto marginale (\% sul totale dei voti validi ai candidati) per schieramento vincente e per area (Camera e Senato)

\begin{tabular}{|c|c|c|c|c|c|c|}
\hline \multirow[t]{2}{*}{ Schieramento } & \multicolumn{3}{|c|}{ Camera } & \multicolumn{3}{|c|}{ Senato } \\
\hline & Nord & Centro & Sud & Nord & Centro & Sud \\
\hline $\begin{array}{l}\mathrm{Fi}+\mathrm{Ln}+\text { Altri } \\
\mathrm{Fi}+\text { An }+ \text { Altri }\end{array}$ & $24,7(161)$ & $27,0(3)$ & $23,1(129)$ & $37,7(73)$ & $38,9(1)$ & $35,6(54)$ \\
\hline $\mathrm{Fi}+$ Altri & & & $513(1)$ & & & \\
\hline An & $39,1(1)$ & & $48,1(7)$ & & & \\
\hline Patto & & & $44,3(4)$ & & & $34,5(3)$ \\
\hline Progressisti & $23,1(14)$ & $26,5(77)$ & $31,6(73)$ & $35,5(10)$ & $34,8(39)$ & $36,9(48)$ \\
\hline Altri & $12,7(4)$ & & $42,4(1)$ & $33,4(4)$ & & \\
\hline Totali & $24,4(180)$ & $26,6(80)$ & $27,4(215)$ & $37,3(87)$ & $34,9(40)$ & $36,1(105)$ \\
\hline
\end{tabular}

Tra parentesi il numero dei casi.

a modelli di competizione nazionali. Il voto residuale è per l'appunto questo indicatore (Tab. 21).

Rispetto al voto marginale, la differenza tra Camera e Senato è ancora più marcata. Alla Camera il voto è concentrato quasi interamente sui primi quattro candidati, lasciando poco spazio agli altri. Come nel caso del voto marginale, le differenze territoriali sono minime. Anche al Sud alla Camera, e questo è sorprendente soprattutto se confrontato con quanto avviene al Senato, il voto residuale è solo il $3,88 \%$ del voto totale. Al Senato invece troviamo una quota consistente di voti residuali, per di più superiore (di poco) al Nord rispetto al Sud. Ma questo dato è meno sorprendente perché sappiamo che il numero medio dei candidati nei collegi del Nord è più alto che al Sud. In questo caso la relazione «più candidati, meno concentrazione del voto» tiene.

TAB. 21. Il voto residuale (\% sul totale dei voti validi ai candidati) per area (Camera $e$ Senato)

\begin{tabular}{lcccc}
\hline & \multicolumn{4}{c}{ Area } \\
\cline { 2 - 5 } & $\begin{array}{c}\text { Nord } \\
\%\end{array}$ & $\begin{array}{c}\text { Centro } \\
\%\end{array}$ & $\begin{array}{c}\text { Sud } \\
\%\end{array}$ & $\begin{array}{c}\text { Italia } \\
\%\end{array}$ \\
\hline Camera & 1,8 & 1,6 & 3,9 & 2,7 \\
Senato & 15,1 & 10,6 & 14,4 & 14,0 \\
Cam. + Sen. & 6,2 & 4,6 & 7,3 & 6,4 \\
\hline
\end{tabular}


TAB. 22. Il voto residuale per schieramento vincente (Camera e Senato)

\begin{tabular}{lrrrrr}
\hline & \multicolumn{2}{c}{ Camera } & & \multicolumn{2}{c}{ Senato } \\
\cline { 2 - 3 } \cline { 5 - 6 } schieramento & $\begin{array}{l}\text { \% voto } \\
\text { residuale }\end{array}$ & $\begin{array}{c}\text { seggi } \\
\text { vinti }\end{array}$ & & $\begin{array}{c}\text { \% voto } \\
\text { residuale }\end{array}$ & $\begin{array}{c}\text { seggi } \\
\text { vinti }\end{array}$ \\
\hline Progressisti & 3,01 & 164 & & 12,06 & 97 \\
Patto & 9,01 & 4 & & 12,01 & 3 \\
Pl & 1,08 & 164 & & 15,06 & 74 \\
Pbg & 2,07 & 129 & & 14,07 & 54 \\
Forza Italia + Altri & 16,05 & 1 & & - & - \\
An & 10,05 & 8 & & - & - \\
Altri & 1,04 & 5 & & 10,04 & 4 \\
Tutti & 2,07 & 475 & & 14,00 & 232 \\
\hline
\end{tabular}

Neanche nel caso del voto residuale esiste relazione significativa con lo schieramento vincente. La presenza di un forte voto residuale diminuisce il livello della soglia di vittoria, ma non sembra differenziare le vittorie dei poli di destra da quelle dei progressisti. Al Senato il voto residuale è alto, ma è alto sempre per tutti (Tab. 22).

Certo si può sostenere l'ipotesi che il voto residuale al Senato indebolisca $i$ candidati moderati sottraendo loro voti e quindi abbassando la soglia di vittoria a favore dei Progressisti. $\mathrm{Ma}$ occorre dimostrare che il voto residuale sia un voto potenzialmente moderato e che in assenza di candidati marginali sia disponibile ad indirizzarsi verso i candidati dei poli di destra. $\mathrm{Ma}$ questa dimostrazione non c'è ancora.

$\mathrm{Al}$ di là dei primi quattro candidati, quanta parte dell'area elettorale marginale va a candidati di formazioni in qualche modo nazionali o importanti e quanta invece si convoglia su candidati periferici, di estrazione locale, candidati «fai-da-te» ecc.? $\mathrm{E}$ questo che abbiamo definito come voto disperso (Tab. 23).

Questi dati non modificano il quadro tracciato finora tranne che per un elemento importante: al Senato al Sud il voto disperso coincide quasi interamente con il voto residuale. Nonostante che in questa zona il numero dei candidati minori sia più basso che al Nord, essi raccolgono una quota più consistente di voti. Ora, dato che è proprio questa la zona più competitiva, è plausibile che una delle ragioni di questa maggiore competitività sia proprio la presenza significativa di questo tipo di voto, anche se dobbiamo aggiungere che questo non si verifica al Nord dove la 
TAB. 23. Il voto disperso (\% sul totale dei voti validi ai candidati) per area (Camera e Senato)

\begin{tabular}{lcccc}
\hline & \multicolumn{4}{c}{ Area } \\
\cline { 2 - 5 } & $\begin{array}{c}\text { Nord } \\
\%\end{array}$ & $\begin{array}{c}\text { Centro } \\
\%\end{array}$ & $\begin{array}{c}\text { Sud } \\
\%\end{array}$ & $\begin{array}{c}\text { Italia } \\
\%\end{array}$ \\
\hline Camera & 0,28 & 0,07 & 1,10 & 0,61 \\
Senato & 9,54 & 8,02 & 12,66 & 10,69 \\
Cam. + Sen. & 3,29 & 2,72 & 4,89 & 3,92 \\
\hline
\end{tabular}

supremazia di Forza Italia/Lega Nord è scalfita, ma non minacciata pur in presenza di un $9,54 \%$ di voto disperso.

La relazione tra competitività e voto disperso al Senato (ma non alla Camera) è confermata dalla correlazione tra questo voto e la differenza primo-secondo. I collegi con la più alta percentuale di voto disperso sono quelli dove la competizione tra $\mathrm{i}$ primi due concorrenti è maggiore (Tab. 24).

In conclusione, il voto disperso è sicuramente un elemento importante di valutazione di queste elezioni. Più che gli altri tipi di voto analizzati qui, è una spia importante di volatilità diffusa. Soprattutto al Sud, in assenza di una forza politica dominante dopo il declino Dc e data la natura regionalista del sistema elettorale per il Senato, la presenza di numerosi candidati locali capaci di raccogliere complessivamente quote non irrilevanti di consenso, ha prodotto un significativo abbassamento della soglia di vittoria nei collegi maggioritari e conseguentemente un aumento della competitività elettorale. La conseguen$\mathrm{za}$ è stato un risultato elettorale più equilibrato (rispetto al Nord e al Centro) tra schieramento progressista che in questa zona ha ottenuto il $45,7 \%$ dei seggi maggioritari e schieramento di destra che ne ha avuti il $51,4 \%$.

Resta però da dimostrare che il voto disperso sia un voto tendenzialmente e prevalentemente moderato e quindi potenzialmente capace in prospettiva di spostare l'equilibrio elettorale in questa zona a favore della destra. In altre parole, è corretto affermare che l'abbassamento della soglia di vittoria favorisce i Progressisti? Se così fosse, si dovrebbe anche concludere che la possibile futura diminuzione del voto disperso favorirà la destra $\mathrm{e}$ contribuirà a porre fine all'anomalia di un Sud competitivo di fronte ad un Nord e ad un Centro che non lo sono affatto. 
ТАВ. 24. Media del voto disperso (\%) per classi di distanza di voto tra primi e secondi candidati di collegio (Camera e Senato)

\begin{tabular}{|c|c|c|c|c|}
\hline \multirow[t]{2}{*}{ Distanza } & \multicolumn{2}{|c|}{ Camera } & \multicolumn{2}{|c|}{ Senato } \\
\hline & $\%$ media & casi & $\%$ media & casi \\
\hline $0.4 \%$ & 1,48 & 64 & 12,75 & 46 \\
\hline $4-8 \%$ & 1,16 & 74 & 11,88 & 44 \\
\hline $8-12 \%$ & 0,43 & 59 & 10,55 & 30 \\
\hline $12-16 \%$ & 0,63 & 57 & 11,58 & 25 \\
\hline $16-20 \%$ & 0,30 & 30 & 9,86 & 23 \\
\hline $20-24 \%$ & 0,26 & 41 & 8,58 & 25 \\
\hline $24-28 \%$ & 0,31 & 47 & 9,03 & 16 \\
\hline $28-32 \%$ & 0,05 & 31 & 7,91 & 9 \\
\hline $32-36 \%$ & 0,38 & 23 & 6,41 & 6 \\
\hline $36.40 \%$ & 0,03 & 19 & 8,65 & 4 \\
\hline $40-44 \%$ & 1,72 & 16 & 7,20 & 2 \\
\hline $44 \cdot 48 \%$ & 2,96 & 9 & & 0 \\
\hline$>48 \%$ & 0,92 & 5 & 10,65 & 2 \\
\hline
\end{tabular}

Ma quali dati possiamo utilizzare per verificare l'ipotesi di un voto disperso di stampo moderato. Una spia è rappresentata dal confronto tra le percentuali medie di voto dei candidati vincenti del Polo del buon governo alla Camera $(44,4 \%)$ e al Senato $(36,2)$ nel Sud. Perché la soglia di vittoria al Senato è tanto più bassa? Una risposta plausibile è che alla Camera il voto disperso è solo dell'1,1\%, mentre al Senato è del 12,66\%.

Per i Progressisti la situazione è nettamente diversa. Alla Camera vincono con una media del $37,8 \%$ e al Senato con il $35,1 \%$. Ora, mentre con il $37,8 \%$ ottengono solo il $33,9 \%$ dei seggi maggioritari alla Camera, con il $35,1 \%$ al Senato ne vincono il $45,7 \%$. L'abbassamento della soglia quindi avvantaggia nettamente i Progressisti. L'ipotesi è che essi abbiano uno zoccolo di voti intorno al 35\% contro il 40 e passa \% del Polo del buon governo e che solo il voto disperso (presente al Senato ma non alla Camera) consenta ai Progressisti di essere più competitivi con i loro avversari moderati.

Anche al Nord la soglia di vittoria si abbassa considerevolmente al Senato rispetto alla Camera, come abbiamo già visto, ma qui i Progressisti non riescono ad approfittarne perché il distacco tra il loro zoccolo e quello del Polo delle libertà è troppo elevato in partenza perché il voto disperso, che pure è elevato (il $9,5 \%$ al Senato contro lo $0,3 \%$ alla Camera), possa fare una differenza.

Questa analisi è corroborata dai dati della tabella 25 sui voti 
TAB. 25. Percentuale media di voti ai candidati nei collegi uninominali per schieramento $e$ area (Camera e Senato)

\begin{tabular}{|c|c|c|c|c|c|c|}
\hline \multirow[b]{2}{*}{ Schieramento } & \multicolumn{2}{|c|}{ Nord } & \multicolumn{2}{|c|}{ Centro } & \multicolumn{2}{|c|}{ Sud } \\
\hline & $\underset{\%}{\substack{\text { Camera } \\
\%}}$ & $\begin{array}{c}\text { Senato } \\
\%\end{array}$ & $\underset{\%}{\substack{\text { Camera } \\
\%}}$ & $\begin{array}{c}\text { Senato } \\
\%\end{array}$ & $\underset{\%}{\substack{\text { Camera } \\
\%}}$ & $\underset{\%}{\text { Senato }}$ \\
\hline Progressisti & 23,7 & 22,9 & 45,0 & 45,0 & 30,5 & 31,4 \\
\hline Patto & 14,8 & 15,3 & 14,6 & 15,4 & 15,4 & 16,4 \\
\hline $\mathrm{Pl}$ & 45,7 & 36,7 & 23,0 & 18,5 & - & - \\
\hline $\mathrm{Pbg}$ & - & - & $33,1^{1}$ & - & 37,4 & 32,6 \\
\hline
\end{tabular}

1 Solo Umbria; in Emilia Romagna, Toscana e Marche il Pbg infatti non c'era.

ottenuti in media dai candidati dei vari schieramenti nelle tre diverse zone. I Progressisti ottengono mediamente il $23 \%$ circa dei voti al Nord (tra Camera e Senato la differenza è minima) e il $30 \%$ circa al Sud. Da sole queste cifre suggeriscono la debolezza «strutturale» dei Progressisti al Nord che li mette nella condizione di non poter approfittare della concorrenza che il voto disperso fa ai loro avversari del Polo delle libertà. Al Sud invece la percentuale media del $30 \%$ costituisce una base dalla quale essi sono riusciti a vincere un certo numero di collegi marginali che hanno limitato la vittoria delle destre alla Camera e creato le condizioni di un Parlamento diviso.

Un altro modo di controllare l'ipotesi che il voto disperso sia di stampo moderato è quello di verificare se esiste una correlazione tra voto disperso e voti ai candidati del Polo del buon governo. Se esistesse una correlazione significativa infatti dovremmo trovare che $\mathrm{i}$ candidati del Polo ottengono meno voti proprio dove il voto disperso è più elevato. La figura 2 mette in luce che una correlazione inversa tra queste due variabili esiste. Il suo valore è di $-0,378$ che corrisponde ad una varianza spiegata di circa il $14 \%$. Il dato è tanto più significativo se lo confrontiamo con il valore di 0,0122 della correlazione tra percentuale di voto ai candidati progressisti e livello del voto disperso il che sta ad indicare che queste due variabili sono effettivamente indipendenti.

\section{I modelli di competizione}

Più di una volta nel corso di questo lavoro abbiamo fatto ri- 


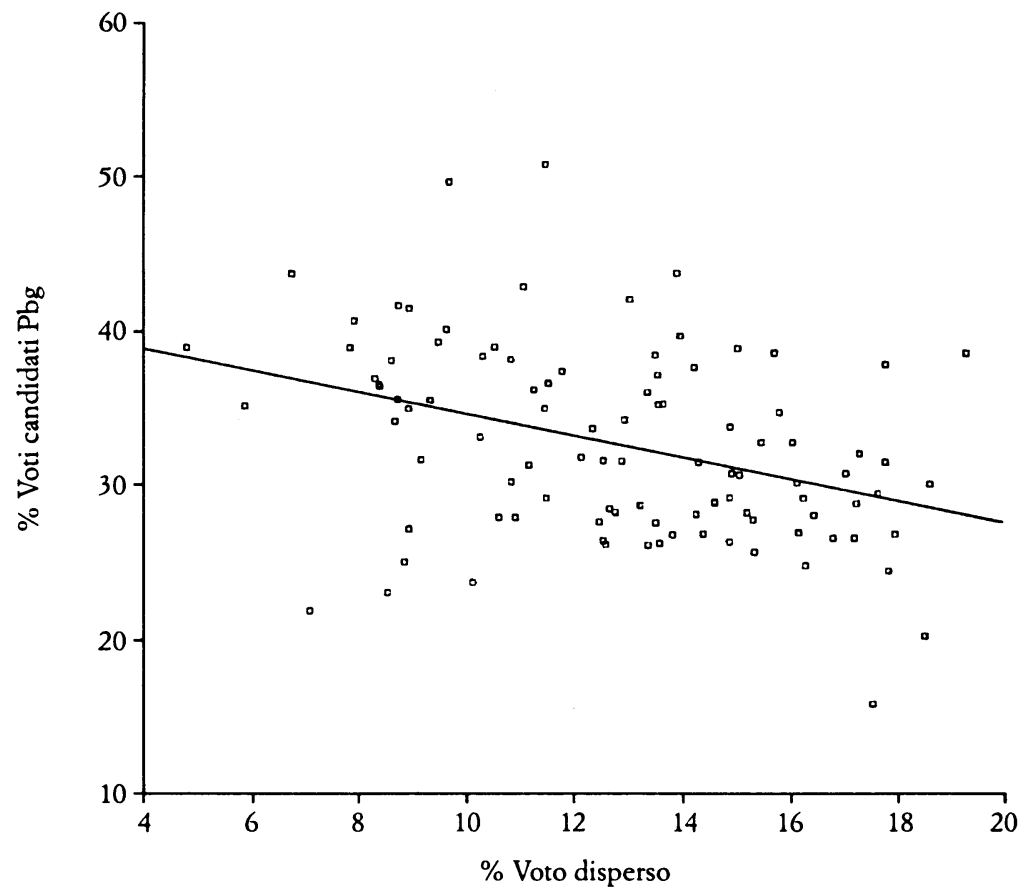

FIG. 2. \% di voti ai candidati del Pbg per \% di voto disperso.

ferimento alle diverse configurazioni che hanno assunto gli scontri tra candidati nei collegi uninominali. In questa sezione affronteremo l'argomento in maniera sistematica facendo riferimento a queste configurazioni come a veri e propri «modelli di competizione». Infatti, una delle caratteristiche di queste elezioni è l'assenza di un modello nazionale di competizione elettorale, dove per nazionale intendiamo una configurazione tipica su tutto o quasi il territorio del Paese dello scontro tra i candidatirappresentanti di partiti nazionali.

Invece, è avvenuto che, accanto ai partiti nazionali (che pure ci sono), troviamo movimenti-partiti locali ovvero candidati indipendenti, e soprattutto gli stessi partiti nazionali si sono presentati agli elettori collegati in alleanze diverse in diverse zone del Paese. Così, la frammentazione dell'offerta da una parte e la caratterizzazione territoriale delle coalizioni elettorali dall'altra hanno prodotto un mosaico di modelli di competizione 
che fanno di queste elezioni un caso raro, se non unico, di «competizione a geografia variabile» (Di Virgilio 1994). Da questo mosaico abbiamo estrapolato tre modelli-base e tre varianti tenendo presenti nella nostra analisi i quattro candidati che in ciascun collegio hanno dimostrato alla prova del voto di essere i più competitivi (Tab. 26) ${ }^{9}$.

Il primo di questi modelli può essere definito come il «modello Centro-Nord». La sua caratteristica principale è la divisione sistematica dello schieramento di destra. Alleanza Nazionale presenta candidati propri in quasi tutti i collegi del CentroNord. Eppure, nonostante questa concorrenza, Forza Italia e Lega Nord riescono ad ottenere nel Nord la grandissima maggioranza dei seggi alla Camera. Al Senato, però, questa maggioranza si riduce a conferma ulteriore della maggiore competitività della sinistra in questa arena. Lungi dall'essere stato un elemento di debolezza, questa divisione si è rivelata una mossa tattica vincente.

Questo modello caratterizza la competizione elettorale non solo al Nord, ma anche al Centro. E qui naturalmente l'esito cambia. La sinistra vince quasi tutti i seggi lasciando al Polo delle libertà soltanto tre seggi alla Camera in Emilia e uno al Senato nella stessa circoscrizione. Qui la divisione della destra fa una differenza. In Toscana e soprattutto nelle Marche è molto improbabile che i Progressisti avrebbero fatto il pieno dei seggi se la destra fosse stata unita. A sostegno di questa ipotesi si possono citare la bassa soglia di vittoria e la modesta differenza tra il candidato vincente progressista e il secondo arrivato.

Il modello Centro-Nord ha una variante (di non grande peso numerico) che è data dalla presenza di «altri» candidati che in 10 casi alla Camera e in 15 al Senato riescono ad escludere il candidato di An dalle prime quattro posizioni. Anche così però l'esito non cambia.

La struttura della competizione al Sud è molto più articolata. Intanto i modelli-base sono due perché qui, a differenza che nel Centro-Nord, la destra è a volte unita e a volte divisa (modelli 3 e 6). Poi c'è la lista Pannella che si alterna con i candidati «altri» nell'influenzare l'esito degli scontri maggioritari (modelli 4 e 5).

9 Nel modello 4 i candidati sono solo 3 perché o il quarto era mancante o, pur essendo presente, non soddisfaceva i criteri di rilevanza per l'inclusione nel nostro file. Questi criteri sono quelli descritti sopra in relazione alla definizione del voto disperso. 
TAв. 26. Candidati vincenti nei collegi uninominali a seconda dei modelli di competizione e della loro collocazione ideologica (Camera e Senato)

\begin{tabular}{|c|c|c|c|c|c|c|c|c|}
\hline \multirow{3}{*}{$\mathrm{N}$} & \multirow{3}{*}{ Modelli-base } & \multirow{3}{*}{ Varianti } & \multicolumn{3}{|c|}{ Camera: candidati vincenti } & \multicolumn{3}{|c|}{ Senato: candidati vincenti } \\
\hline & & & Sinistra $^{1}$ & Destra 2 & Totale $^{3}$ & Sinistra ${ }^{1}$ & Destra $^{2}$ & Totale $^{3}$ \\
\hline & & & $\%$ & $\mathrm{~N}$ & $N$ & $\%$ & $N$ & $\mathrm{~N}$ \\
\hline
\end{tabular}

$\mathrm{F} / \mathrm{Ln}+$

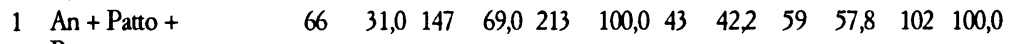

Prog.

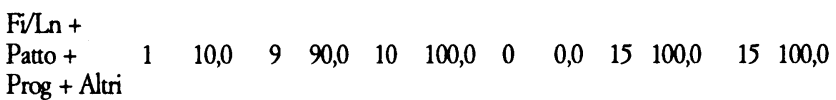

$\mathrm{F} / \mathrm{An}+$

3 Patto+

Prog. + Altri

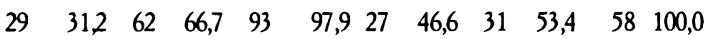

\begin{tabular}{|c|c|c|c|c|c|c|c|c|c|c|c|c|}
\hline 4 & $\begin{array}{l}\text { Fv/An + } \\
\text { Patto+ } \\
\text { Prog. + Lp }\end{array}$ & 5 & 19,2 & 21 & 80,8 & 26 & 100,0 & 8 & 27,6 & 21 & 72,4 & 29 \\
\hline & $\begin{array}{l}\text { FVAN + } \\
\text { Patto+ } \\
\text { Prog. }\end{array}$ & 21 & 35,0 & 39 & 65,0 & 60 & 100,0 & 8 & 66,7 & 2 & 16,7 & 12 \\
\hline
\end{tabular}

$\mathrm{FI}+\mathrm{AN}+$

$\begin{array}{lllllllllllll}6 \text { Patto+ } & 31 & 75,6 & 8 & 19,5 & 41 & 95,1 & 5 & 100,0 & 0 & 0,0 & 5 & 100,0\end{array}$

Prog.

1 Sinistra $=$ Progressisti.

2 Destra $=$ Polo delle Libertà, Polo del buon governo e loro varianti.

3 Laddove il totale percentuale non corrisponde a 100 significa che almeno un seggio è andato a candidati non collegati né ai Progressisti, né ai Poli.

Al Sud la divisione delle destre non paga. Questo è il dato più evidente (modello 6). Sui 41 scontri di questo modello alla Camera i Progressisti ne vincono ben 31 (il 75,6\%!). Al Senato addirittura il $100 \%$, ma i casi sono pochi perché la destra al Senato non era divisa ${ }^{10}$.

Quando la destra è unita, la competizione è più serrata, ma la sinistra resta competitiva. La sorpresa è rappresentata dalla Lista Pannella (Lp). Il suo successo (relativo) fa una importante differenza. Infatti, il Pbg va meglio quando il candidato della

${ }_{10}$ Due seggi vanno al Patto. 
Lp entra tra i primi quattro (modello 4). In questo caso, su 26 seggi alla Camera ne prende 21 e su 29 al Senato ne vince ugualmente 21 .

L'esito della competizione destra-sinistra è invece nettamente diverso (vale a dire, più equilibrato) quando, al posto del candidato della $L p$, il quarto è rappresentato da un candidato appartenente alla categoria degli «altri» (modello 3). Sembra quindi che la Lp sottragga voti a sinistra (ma è una ipotesi in attesa di ulteriori verifiche), mentre $\mathrm{i}$ candidati indipendenti sottraggono voti a destra. Quest'ultimo dato è corroborato anche dalla nostra analisi sul voto disperso. Ed è proprio allo scarso peso di questo voto alla Camera che si deve probabilmente il fatto che lo stesso modello di competizione produce qui un risultato così diverso.

L'ultimo modello da considerare (modello 5) è quello degli scontri a tre. Il quarto manca perché non soddisfa i nostri criteri di rilevanza. Questo modello rappresenta un puzzle, in parte forse dovuto alla esiguità dei casi al Senato. Alla Camera (60 casi) l'assenza del quarto concorrente si accompagna al predominio della destra con una percentuale di vittorie non dissimile da quella del modello 3 dove compare un «altro» candidato come quarto. Resta però che con questo modello la sinistra fa meglio che nella «variante Pannella». Al Senato la situazione è ribaltata a favore della sinistra che vince 8 seggi su 12, ma i casi sono pochi per trarne delle conclusioni attendibili.

In sintesi, l'analisi dei modelli di competizione ci ha permesso di fermare questi punti (alcuni dei quali sono conferme di osservazioni già fatte in precedenza):

1. la sinistra è più competitiva al Senato;

2. la destra divisa (modello 6) perde alla Camera un numero rilevante di seggi che non avrebbe altrimenti perso;

3. il ruolo della Lista Pannella: i candidati di questa lista entrano tra $\mathrm{i}$ primi quattro 35 volte alla Camera e 30 volte al Senato; la loro competitività si associa ad un pessimo andamento della sinistra;

4. la presenza di candidati indipendenti («gli altri») (modello 3) è un fattore molto più favorevole alla sinistra al Senato rispetto alla Camera. 
Cartelli elettorali e comportamenti di voto

Uno degli aspetti più interessanti di queste elezioni è rappresentato dal fatto che i protagonisti della competizione elettorale non fossero partiti, ma coalizioni di partiti ovvero «cartelli elettorali». Questi cartelli si sono fondati su accordi di spartizione delle candidature nei collegi uninominali realizzati in modo tale che in ciascun collegio ci fosse un unico candidato rappresentante il cartello, ma appartenente ad una delle sue componenti. Qui non ci interessa studiare il processo di formazione di questi cartelli né i criteri che hanno regolato all'interno di ciascuno di essi la distribuzione delle candidature comuni (Di Virgilio 1994). Ci interessa invece studiare come questi cartelli hanno funzionato elettoralmente $\mathrm{e}$ in particolare come gli elettori hanno reagito alle scelte sulle candidature effettuate dai vari schieramenti. In altre parole, in che misura il candidato di ciascun schieramento è stato accettato o rifiutato dagli elettori potenziali di quello schieramento? Per fare un esempio concreto, in che misura il candidato di Rifondazione Comunista o quello di Alleanza Nazionale hanno ricevuto tutti i voti del cartello progressista o di quello del Polo del buon governo?

Queste domande servono a farci riflettere su un'altra dimensione della competitività elettorale, quella legata alla «qualità» dei candidati messi in campo dai diversi cartelli. Naturalmente la qualità delle candidature dipende da molti fattori, la maggior parte dei quali non ci è possibile analizzare in questa sede con i dati a nostra disposizione. Esiste però un aspetto importante su cui i nostri dati quantitativi possono dare delle indicazioni utili: la misura in cui $i$ candidati di ciascun schieramento sono stati capaci (1) di «fare il pieno» dei voti dello schieramento di appartenenza ed eventualmente (2) di «pescare voti» al di fuori della propria area elettorale. Ci riferiremo a queste due «qualità» come alla capacità di mobilitazione interna e alla capacità di attrazione esterna dei candidati di ciascun cartello.

Incrociando queste due variabili possiamo identificare diversi tipi di candidati. Il «buon candidato» è quello che riesce a mobilitare tutto il voto del proprio schieramento senza perderne quote per strada. Il «candidato eccellente» è quello che oltre a mobilitare il proprio elettorato di riferimento è capace di attrarre voti che altrimenti andrebbero altrove. Il «candidato senza qualità» è quello che non solo non pesca voti all'esterno, ma non fa nemmeno il pieno dei voti all'interno del suo blocco 
elettorale. Sono gli elettori quindi che giudicano la qualità delle candidature di cartello, accettandole ovvero respingendole. In questo ultimo caso, gli elettori preferiscono la defezione. La defezione è quindi l'altra faccia del fenomeno che abbiamo definito come capacità di mobilitazione interna. Un elevato tasso di defezione sta ad indicare una bassa capacità di mobilitazione e per converso una bassa disciplina coalizionale degli elettori. Uno schieramento che soffre di un basso tasso di disciplina interna (dal punto di vista degli elettori, non delle élite che potrebbero essere disciplinatissime, ma trovarsi senza esercito) è uno schieramento meno competitivo di altri. $\mathrm{O}$ se preferiamo non usare il termine competitivo, possiamo dire che è uno schieramento a rischio.

Ciò premesso, occorre una precisazione. Non necessariamente il buon candidato o il candidato eccellente sono candidati competitivi nel senso che abbiamo attribuito al termine finora, vale a dire candidati in grado di vincere. Anzi, potrebbe essere che il «candidato senza qualità» sia un candidato competitivo, cioè vincente, perché si trova in un collegio sicuro. Pur tuttavia in un altro senso si può, e a nostro avviso si deve, parlare di competitività dei candidati anche facendo riferimento alla loro capacità di mobilitazione interna e di attrazione esterna, indipendentemente dalla loro possibilità di vittoria. Parliamo in questo caso di un'altra, e diversa, dimensione della competitività elettorale, ma pur sempre una dimensione rilevante perché capace di cogliere aspetti non marginali dell'esito della competizione e delle prospettive future degli schieramenti in campo.

Per indagare questi aspetti della competizione elettorale la prima elaborazione che faremo si basa sul confronto tra il voto medio (\%) ottenuto da tutti i candidati del cartello elettorale (voto del cartello) e il voto medio (\%) ottenuto dai candidati di ciascuna componente del cartello (voto dei candidati del cartello). Nel caso del voto del cartello, il dato è quello che risulta dalla somma dei voti a tutti i candidati del cartello (vincenti e perdenti) in tutti i collegi in cui il cartello era presente. Nel caso del voto dei candidati del cartello, il dato concerne solo i voti ottenuti in media dai candidati (vincenti e perdenti) di ciascuna componente del cartello in tutti i collegi in cui il cartello era presente con un candidato di quella componente. Per questa analisi abbiamo preso in considerazione solo tre cartelli: Progressisti, Polo delle libertà $(\mathrm{Pl})$ e Polo del buon governo (Pbg) (Tab. 27). 
TAB. 27. Voto medio dei candidati uninominali per cartello elettorale e per ogni sua componente (Camera e Senato)

\begin{tabular}{|c|c|c|c|c|}
\hline \multirow[b]{2}{*}{$\begin{array}{l}\text { Cartello e sue } \\
\text { componenti }\end{array}$} & \multicolumn{2}{|c|}{ Camera } & \multicolumn{2}{|c|}{ Senato } \\
\hline & $\begin{array}{l}\% \text { media } \\
\text { di voti }^{1}\end{array}$ & $\begin{array}{c}\mathrm{N} \\
\mathrm{casi}^{2}\end{array}$ & $\begin{array}{l}\% \text { media } \\
\text { di voti }^{1}\end{array}$ & $\begin{array}{c}\mathrm{N} \\
\text { casi }^{2}\end{array}$ \\
\hline Forza Italia & 37,8 & 61 & 27,1 & 34 \\
\hline Lega Nord & 41,1 & 148 & 33,1 & 83 \\
\hline Ccd & 34,1 & 15 & 31,8 & 3 \\
\hline Udc & 49,6 & 3 & 45,6 & 1 \\
\hline Riformatori & 47,8 & 6 & 34,3 & 1 \\
\hline Pld & 49,7 & 2 & - & - \\
\hline Polo Libertà & 40,1 & 235 & 31,5 & 122 \\
\hline Forza Italia & 35,9 & 63 & 31,4 & 28 \\
\hline An & 37,8 & 102 & 33,8 & 52 \\
\hline Ccd & 38,8 & 21 & 30,9 & 17 \\
\hline Udc & 30,4 & 1 & 34,6 & 2 \\
\hline Polo Buon Gov. & 37,2 & 188 & 32,6 & 99 \\
\hline Ind. Sin. & 25,2 & 49 & 26,8 & 16 \\
\hline Pds & 32,2 & 182 & 33,0 & 94 \\
\hline Rc & 31,1 & 58 & 30,4 & 31 \\
\hline Psi & 30,1 & 38 & 28,8 & 23 \\
\hline Verdi & 32,2 & 31 & 29,5 & 14 \\
\hline Ad & 31,4 & 49 & 30,2 & 20 \\
\hline Rete & 27,6 & 39 & 27,2 & 14 \\
\hline Cs & 29,3 & 20 & 31,6 & 12 \\
\hline Rs & 30,9 & 2 & 39,7 & 1 \\
\hline Progressisti & 30,4 & 473 & 30,5 & 232 \\
\hline
\end{tabular}

1 Calcolata sui votanti.

${ }^{2}$ La somma dei candidati delle singole componenti può non corrispondere al totale delle candidature di cartello a causa di alcuni dati mancanti.

Cominciamo dal Pl. Un dato che avevamo già, ma che qui trova ulteriore conferma, è la forte differenza tra voto medio alla Camera e al Senato. Nuovi sono invece i dati sui rendimenti delle diverse formazioni all'interno del cartello. In entrambe le Camere, i candidati di Fi ottengono un voto medio considerevolmente più basso di quello dei candidati della $\operatorname{Ln}$ (il $37,8 \%$ contro il $41,1 \%$ ) e più basso anche della media del cartello $(40,1 \%)$. Alla Camera lo stesso vale per i candidati del Ccd, 
mentre per i candidati Uc, Riformatori e Pld è il contrario (ma i casi, anche se significativi, sono pochi).

$\mathrm{Nel} \mathrm{Pbg}$ si ripete in parte lo stesso copione che abbiamo visto nel Pl. All'interno della coalizione i candidati di Fi raccolgono mediamente meno dei candidati di An sia alla Camera che al Senato e meno del voto medio del cartello. Diverso il caso dei candidati Ccd che alla Camera raccolgono mediamente molti più voti $(38,8 \%)$ dei loro colleghi che si sono presentati con il $\mathrm{Pl}$ facendo anche meglio di An che ottiene il 37,8. Ma questo risultato del Ccd non si ripete al Senato. Tra le due Camere la differenza è di quasi 8 punti. A proposito del Senato, merita sottolineare che il voto medio dei candidati di Fi e di An è superiore a quello dei candidati di Fi e della Ln nel Pl e lo stesso voto medio del $\mathrm{Pbg}$ è superiore al voto medio del $\mathrm{Pl}$.

Passando ai Progressisti, notiamo subito - ed è anche questa una conferma - che la differenza tra voto medio ai candidati alla Camera e voto medio ai candidati al Senato scompare e si riduce di molto al Senato la distanza tra questo schieramento e gli altri due. All'interno del cartello, di fronte ad un voto medio di gruppo alla Camera del $30,4 \%$, vanno bene i candidati del Pds $(32,2 \%)$, dei Verdi $(32,2 \%)$, di Ad $(31,4 \%)$ e anche di Rc $(31,1 \%)$. Inferiore alla media della coalizione è il voto ai candidati Is $(25,2 \%)$, Rete $(27,6 \%)$, Cs $(29,3 \%)$ e Psi $(30,1 \%)$. Al Senato il quadro è leggermente diverso. I candidati $\mathrm{Pds}$ sono sopra la media del cartello, così come i Cs, mentre Rete e Is sono sempre sotto. I candidati di Rc e di Ad presentano valori medi più vicini alla media di cartello rispetto alla Camera. Psi e Verdi invece vanno sotto la media, mentre alla Camera erano sopra.

Dai dati della tabella 27 possiamo trarre la conclusione valida per tutti e tre $\mathrm{i}$ cartelli analizzati - che i candidati di ciascuna componente di ogni cartello hanno dimostrato rendimenti diversi. In qualche caso notevolmente diversi. In qualche caso anche sorprendenti, vedi infatti il comportamento dei candidati di An e di Rc. Trattandosi di partiti collocati agli estremi dello spazio politico potremmo aspettarci un maggior numero di defezioni da parte di elettori moderati dei rispettivi cartelli. Invece i dati che abbiamo visto dimostrano in prima approssimazione che in entrambi i casi i candidati di questi partiti hanno potuto godere di una notevole fedeltà da parte degli elettori del cartello. Se così non fosse stato, avremmo dovuto rilevare un voto medio ai candidati di An e di Rc inferiore, e non superiore, rispetto a quello del voto medio dei candidati del cartello. Allora, 
come possiamo spiegarci questo comportamento apparentemente anomalo? Più in generale, come possiamo spiegarci la varianza all'interno di ciascun cartello?

La spiegazione non può prescindere dalla natura dei collegi dove $i$ diversi candidati si sono presentati. Non tutti i collegi sono uguali dal punto di vista delle possibilità di successo dei candidati di diversi partiti. In realtà, la qualità del candidato la sua competitività - potrebbe essere una funzione non delle sue caratteristiche personali, ma della «qualità» del suo collegio. La differenziazione territoriale del voto conferma che le cose stanno effettivamente in questi termini. Ma anche all'interno di zone omogenee - il Nord e il Centro - non tutti i collegi sono uguali. Insomma, il buon collegio, il collegio sicuro, fa il buon candidato. Non sarà sempre così probabilmente, e nel Sud non lo è, ma per ora il sistema maggioritario non ha ancora prodotto una personalizzazione del voto tale da rendere il candidato più importante della forza politica cui appartiene. Quindi è sbagliato affermare che, per esempio, i candidati di $\mathrm{Fi}$ il cui voto è mediamente inferiore a quelli della $\mathrm{Ln}$ e di An sono meno competitivi, meno capaci di mobilitare il voto del proprio elettorato di riferimento. E plausibile infatti che essi, come gli Indipendenti di sinistra all'interno del cartello dei Progressisti, siano stati collocati in collegi più difficili, meno sicuri. In sostanza, le differenze tra voto medio di cartello e voto medio dei candidati di ciascuna sua componente - $\mathrm{i}$ dati della tabella 27 - possono sostenere due ipotesi: 1) che i candidati di quelle formazioni il cui voto è sotto la media sono stati incapaci di mobilitare tutti i voti del cartello e che quindi ci siano state defezioni al suo interno (ipotesi della indisciplina coalizionale degli elettori) oppure 2) che i collegi contino più dei candidati e che i collegi sicuri siano stati assegnati ad alcune formazioni a danno di altre (ipotesi del primato del collegio).

Per controllare queste ipotesi abbiamo a disposizione i dati che ci sono forniti dalla seconda scheda della Camera, il voto di lista. Grazie alla doppia scheda, possiamo confrontare i voti ricevuti da tutti i candidati uninominali di ogni componente di ciascun cartello (naturalmente per i collegi dove i candidati del cartello appartenevano a quella data componente) con i voti di lista raccolti da tutte le liste appartenenti al cartello nei collegi in questione. In altre parole, prendiamo i candidati di Rc che si sono presentati nei collegi uninominali della Camera come rappresentanti del cartello dei Progressisti e calcoliamo il voto me- 
dio che hanno ottenuto; contemporaneamente calcoliamo il voto medio ottenuto negli stessi collegi da tutte le liste progressiste collegate ai candidati di Rc e facciamo il confronto.

In questo confronto il voto di lista è una variabile molto importante perché essa può essere considerata un buon indicatore della qualità (leggi: sicurezza) del collegio. Infatti se le liste progressiste, per continuare con il nostro esempio, ottengono in un dato collegio un'alta percentuale di voti è lecito inferirne che il collegio è un buon collegio per i candidati di sinistra, un collegio sicuro. Dietro questa conclusione c'è però una assunzione importante: che il voto di lista sia un voto sincero, un voto cioè che rispecchia le «vere» preferenze degli elettori o meglio che rispecchia perfettamente la loro scala di preferenze tra le liste in campo. A noi sembra che questa assunzione tenga nel contesto delle elezioni in esame. Al contrario del voto maggioritario è proprio questo tipo di voto che consente all'elettore di affermare ancora una propria specifica identità partitica senza dover ricorrere a complicati calcoli di convenienza strategica (D'Alimonte e Chiaramonte 1993). E molto probabile che questo si sia verificato $^{11}$. Al contrario, è poco plausibile l'ipotesi che gli elettori che rifiutano il candidato uninominale sgradito finiscano con il non votare anche la lista gradita nell'arena proporzionale.

$E$ il voto dei candidati come può essere interpretato? Esso è l'indicatore della loro capacità di mobilitazione interna e di attrazione esterna. Non tutti i candidati sono capaci di «fare il pieno» dei voti del cartello, cioè raccogliere tutto il voto proporzionale delle liste collegate. Né tutti i candidati sono capaci di raccogliere un numero di consensi maggiore di quelli raccolti dalle liste del cartello. Quindi, dal confronto tra voti maggioritari ai candidati e voti proporzionali alle liste possono scaturire tre risultati: 1) il voto dei candidati è superiore a quello delle liste del cartello; 2) il voto delle liste è superiore a quello dei candidati; 3) nessuna differenza tra i due valori. Ognuno di questi risultati ha una diversa rilevanza empirica ${ }^{12}$.

${ }^{11} \mathrm{Si}$ potrebbe però sostenere che l'esistenza di una soglia del $4 \%$ per il riparto proporzionale alla Camera abbia indotto delle defezioni da parte di elettori che non volevano sprecare il proprio voto dandolo ad una lista che percepivano come incapace di superare la soglia. $\grave{E}$ molto probabile che questo fenomeno si sia in parte prodotto. La nostra opinione però è che, almeno in queste elezioni, sia stato un fenomeno marginale. Non c'è dubbio però che questo è un elemento del sistema elettorale di cui sia gli elettori che i partiti in futuro terranno sempre più conto.

${ }_{12}$ Per quanto riguarda le ipotesi soggiacenti alla analisi dei flussi di voto indivi- 
Nel primo caso siamo di fronte a quello che abbiamo defintito come il candidato eccellente: un candidato il cui consenso va al di là di quello delle liste che lo appoggiano. Questo vuol dire che ci sono elettori che lo votano, pur non votando nell'arena proporzionale per nessuna delle liste del cartello cui egli appartiene. Il candidato eccellente somma capacità di mobilitazione e capacità di attrazione. Grazie a quest'ultima produce un effetto di trascinamento a favore dello schieramento cui appartiene che è il prodotto della personalizzazione del voto. Quindi possiamo ipotizzare che un voto di lista superiore al voto maggioritario è la spia dell'esistenza di un voto personale, un voto che si orienta più sulle caratteristiche del candidato invece che sulle affinità di partito o di schieramento.

Il secondo caso è quello del «candidato senza qualità»: non solo non attrae voti esterni, ma non riesce a raccogliere nemmeno i voti del proprio elettorato di riferimento. Questo risultato, che ovviamente danneggia il cartello rendendolo meno competitivo, può dipendere dall'esistenza di due tipi di comportamento di voto: il voto strategico e il voto ideologico. Il voto strategico è il voto di chi sceglie di non votare il candidato uninominale nel proprio collegio perché lo ritiene comunque un perdente. Il voto ideologico è il voto di chi si rifiuta di votare il candidato del proprio cartello perché sgradito (non importa per quale ragione) e quindi si astiene o addirittura vota un candidato di un altro cartello. In entrambi i casi, assumiamo che sia gli elettori strategici che quelli ideologici diano comunque il loro voto proporzionale al partito di appartenenza nell'ambito del cartello. In tal modo la differenza tra i due tipi di voto è una spia della scarsa coesione del cartello e della infedeltà dei suoi elettori.

Il caso più semplice è l'ultimo: quello del buon candidato, il candidato che raccoglie tutti i voti degli elettori del cartello, ma niente di più. Il cartello funziona. Può vincere o perdere, ma comunque la scelta del candidato che lo rappresenta non lo danneggia.

Ciò premesso, vediamo i dati delle tabelle 28 e 29 . Questi dati riferiti rispettivamente a Progressisti, $\mathrm{Pl}$ e $\mathrm{Pbg}$ ci consentono di controllare le ipotesi da cui siamo partiti su coesione dei cartelli, comportamento degli elettori e peso dei candidati. Cominciamo dai Progressisti (Tab. 28).

duali che si nascondono dietro i risultati aggregati la nostra posizione è riassunta nelle pagine del cap. 2 di Bartolini e Mair (1990). 
TAB. 28. Voto medio ai candidati, voti alle liste e tasso di vittoria nei collegi uninominali suddivisi per componente del cartello progressista (Camera)

\begin{tabular}{|c|c|c|c|c|c|c|}
\hline Componenti & $\begin{array}{c}\mathrm{N} \\
\text { collegi }\end{array}$ & $\begin{array}{c}\% \text { media } \\
\text { di voti }^{1} \\
\text { ai candidati } \\
\text { A }\end{array}$ & $\begin{array}{l}\text { \% media } \\
\text { di voti }{ }^{1} \\
\text { alle liste } \\
\mathrm{B}\end{array}$ & $A \cdot B$ & $\begin{array}{c}\text { vittorie } \\
\text { uninominali }\end{array}$ & $\begin{array}{c}\text { tasso } \mathrm{di} \\
\text { vittoria }(\%)\end{array}$ \\
\hline Ind. Sin. & 49 & 25,2 & 25,5 & $-0,3$ & 10 & 20,4 \\
\hline Pds & 182 & 32,2 & 33,7 & $-1,5$ & 72 & 39,6 \\
\hline Rc & 58 & 311 & 33.9 & $-2,8$ & 27 & 46,6 \\
\hline Psi & 38 & 30,1 & 31,6 & $-1,5$ & 14 & 36,8 \\
\hline Verdi & 31 & 32,2 & 32,8 & $-0,6$ & 11 & 35,5 \\
\hline Ad & 49 & 31,4 & 32,6 & $-1,2$ & 18 & 36,7 \\
\hline Rete & 39 & 27,6 & 27,6 & 0 & 6 & 15,4 \\
\hline Cs & 20 & 29,3 & 30,5 & $-1,2$ & 5 & 25,0 \\
\hline Rs & 2 & 30,9 & 30,6 & 0,3 & 1 & 50,0 \\
\hline Progressisti & 468 & 30,6 & 31,9 & $-1,3$ & 164 & 33,0 \\
\hline
\end{tabular}

${ }^{1}$ Calcolata sui votanti.

La prima osservazione da fare riguarda l'assegnazione dei seggi alle varie componenti della coalizione. Rete e Indipendenti di sinistra sono le formazioni più penalizzate. I loro candidati infatti si sono trovati a competere in collegi difficili, dove il voto di sinistra era mediamente più basso ${ }^{13}$. Questo spiega non solo il basso tasso di vittorie di questi candidati (vedi ultima colonna della tabella 28), ma anche il sensibile scostamento tra il loro voto medio e il voto medio del cartello, un dato evidenziato nella tabella 27. In questi casi, trova conferma l'ipotesi che non siano i candidati ad essere senza qualità, ma i collegi. Anzi, i candidati, sia retini che indipendenti, in questi collegi difficili hanno ottenuto un buon risultato relativo visto che $\mathrm{i}$ voti da essi ottenuti nei collegi sono molto vicini (nel caso della Rete uguali) a quelli ottenuti nella proporzionale da tutte le liste del cartello progressista. In altre parole, hanno fatto addirittura meglio dei loro colleghi più fortunati, come quelli del Pds e di Rc, che pure assegnati in collegi buoni (vedi il voto alle liste progressiste in corrispondenza ai voti per i candidati Pds e Rc) hanno preso mediamente meno voti delle liste progressiste.

${ }^{13}$ Nel caso degli indipendenti è stata con tutta probabilità una scelta deliberata. Nel caso della Rete invece hanno giocato un ruolo importante le aspettative sbagliate sul voto in Sicilia. Sull'«enigma siciliano» si veda Ricolfi (1994). 
Questo è il dato più importante della tabella 28: i candidati del cartello di sinistra vanno sistematicamente peggio delle liste progressiste nel loro complesso (a parte i due candidati di Rinascita socialista e i candidati della Rete che, come abbiamo visto, fanno pari). In alcuni casi, lo scostamento tra i due dati è minimo (Verdi e Is), ma in altri casi è sensibile visto che $\mathrm{i}$ candidati di Rc perdono mediamente il $2,8 \%$ dei voti che invece raccolgono le liste del cartello. Ma quello che colpisce di più non sono i singoli confronti, ma il dato complessivo, la sua sistematicità, confermata inequivocabilmente dalla figura 3 . I candidati di sinistra non hanno nessun effetto di trascinamento. Quando va bene (in pochi casi) riescono a mobilitare tutto o quasi il proprio elettorato, ma più in là di questo non vanno. Nessuna capacità di attrazione. Banalmente, ma forse neanche tanto, potremmo vedere in questo risultato la conferma di una delle previsioni più comuni della politica italiana: che divisi si vince e uniti si perde. Ma perché questo dovrebbe essere vero a sinistra, ma non a destra? Perché a destra invece (vedi tabella 29) i candidati vanno meglio delle loro liste di riferimento?

Una delle possibili spiegazioni è che la sommabilità degli elettorati di sinistra è più bassa della capacità coalizionale delle élite. In fondo, pur tra molti contrasti, i tavoli hanno funzionato; nella maggior parte dei casi un accordo è stato trovato sulla spartizione dei collegi nonostante che ben 8 formazioni abbiano partecipato alle trattative. Quando però i risultati di questo accordo (i vari candidati nei vari collegi) sono stati offerti agli elettori, una parte di loro li ha rifiutati. In questo rifiuto giocano certamente molti fattori. Noi li abbiamo sintetizzati in parte con i termini voto ideologico e voto strategico anche se non siamo in grado in questa fase della nostra ricerca di quantificare il loro impatto. Tra i due, probabilmente il voto strategico ha avuto un peso minore. Come detto sopra, questo è il comportamento di quegli elettori che non vogliono «sprecare» il proprio voto votando un candidato che percepiscono come assolutamente non competitivo. $\mathrm{E}$ un tipo di voto che non solo richiede una conoscenza precisa delle regole elettorali, ma anche una buona dose di calcolo razionale.

Il voto ideologico invece è un voto «istintivo». Questo non vuol dire che non abbia una componente razionale. Anzi. Chi decide di non votare un candidato presentato dalla coalizione di riferimento, e nella quale trova il partito che gli è più gradito, lo fa a ragion veduta. E la ragione sta nella distanza ideolo- 


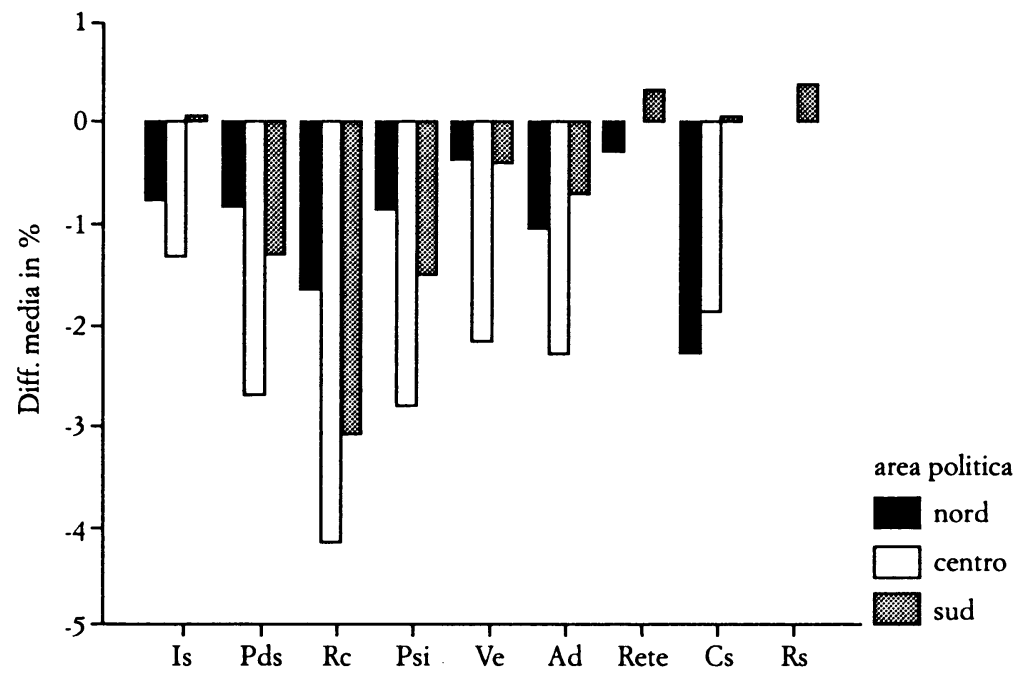

FIG. 3. Differenza tra voti ai candidati e voti alle liste progressiste per area politica (Camera).

gica che separa la sua posizione nello spazio politico da quella del candidato offerto. Anche questo è calcolo razionale, ma è più immediato e perciò piu istintivo, più alla portata dell'elettore medio. Per questo siamo più propensi a credere che il «male oscuro» della sinistra sia da cercare qui, nella sua scarsa coesione ideologica a livello di massa. Il dato di Rc a questo proposito è indicativo. I suoi candidati sono quelli che vanno peggio, pur vincendo. Anzi, il loro tasso di vittoria è il più alto tra tutte le formazioni della sinistra (il $46,6 \%$ dei suoi candidati risulta eletto come emerge dall'ultima colonna della tabella 28). Più alto addirittura di quello del $\mathrm{Pds}$. Ma Rc vince perché è presente in collegi sicuri, non perché i suoi candidati siano veramente competitivi. Al contrario, perdono per strada mediamente il $2,8 \%$ dei voti! $\mathrm{Da}$ dove vengono questi voti persi? $\mathrm{La}$ nostra ipotesi è che siano elettori ideologici, elettori di una sinistra moderata, che trovandosi nel proprio collegio un candidato di Rc semplicemente si rifiutano di votarlo. Ma la stessa ipotesi possiamo applicarla al caso dei candidati di Ad che pure non riescono a mobilitare tutto l'elettorato del cartello progressista. Anche in questo caso è probabile che ci siano elettori, questa volta di estrema sinistra, che considerano il candidato di Ad troppo distante ideologicamente per poterlo votare. 
La distanza ideologica a livello di massa (a livello degli elettori e non delle élite) è una chiave interpretativa importante non solo di questo risultato elettorale per la sinistra, ma anche delle sue prospettive future. La sommabilità degli elettorati di sinistra è quanto meno una condizione necessaria perché la sinistra possa sperare di vincere in futuro. L'abbandono della proporzionale ha reso il problema più acuto. Prima, in epoca proporzionale, questa operazione di somma poteva restare una prerogativa delle élite, non soggetta ad immediate e incerte verifiche elettorali. In regime maggioritario, la verifica elettorale è tutto. La somma si fa lì, non in Parlamento o nelle sedi di partito. Naturalmente, visti i risultati complessivi di queste elezioni, è chiaro che alla sinistra non basta sommare i suoi voti per poter vincere. Ma i dati della tabella 28 suggeriscono che per poter diventare più competitiva la sinistra deve innanzitutto ridurre la sua distanza ideologica interna.

Ben diverso è il caso della destra (Tab. 29). Laddove i Progressisti non erano in grado di mobilitare completamente i voti di sinistra né tantomeno attirarne altri, vediamo che sia nel Pl che nel $\mathrm{Pbg}$ (unica eccezione è Uc nel Pbg, ma è un solo caso) i candidati vanno meglio delle liste. Significativo è il risultato dei candidati di Fi nel Pl $(+3,7 \%)$ e della $\operatorname{Ln}(+3,4 \%)$, ma ancor più significativo è il dato di $\mathrm{An}$ i cui candidati nel $\mathrm{Pbg}$ vanno meglio non solo delle liste $\mathrm{Pbg}(+3,3 \%) \mathrm{ma}$ anche di quelli di Fi che ottengono invece solo lo $0,3 \%$ più dei voti di lista anche se complessivamente sia i candidati di Fi che quelli del Ccd (e anche questo è un dato interessante) prendono più voti maggioritari di quelli di An.

Il dato relativo ad An merita di essere sottolineato perché è una spia significativa della intercambiabilità delle candidature moderate al Sud. Dal punto di vista dell'analisi spaziale ci saremmo dovuti aspettare che $\mathrm{i}$ candidati di An, appartenenti ad un partito collocato alla estrema destra del continuum ideologico, dimostrassero una capacità di mobilitazione minore di candidati quali quelli di Fi. Invece, non è così. Il loro effetto di trascinamento è superiore a quello dei candidati di Fi e anche a quelli del Ccd. Meglio di questi ultimi riescono ad attrarre voti al di là delle liste del polo. A questo si aggiunga che il voto medio di questi candidati $(37,8 \%)$ è superiore a quello dei candidati del $\mathrm{Pbg}(37,2 \%)$ nel suo complesso e che il loro tasso di vittoria $(77,5 \%)$ è superiore sia a quello dei candidati di $\mathrm{Fi}$ $(57,1 \%)$ sia a quello dei candidati del Ccd $(61,9 \%)$. Quest'ulti- 
TAB. 29. Voto medio ai candidati, voti alle liste e tasso di vittoria nei collegi uninominali suddivisi per componente del cartello Polo delle Libertà e del cartello Polo del buon governo (Camera)

\begin{tabular}{lrccccc}
\hline Componenti & $\begin{array}{c}\text { N } \\
\text { collegi }\end{array}$ & $\begin{array}{c}\text { \% media } \\
\text { di voti } \\
\text { ai candidati } \\
\text { A }\end{array}$ & $\begin{array}{c}\text { \% media } \\
\text { di voti }^{1} \\
\text { alle liste } \\
\text { B }\end{array}$ & A - B & $\begin{array}{c}\text { vittorie } \\
\text { uninominali }\end{array}$ & $\begin{array}{c}\text { tasso di } \\
\text { vittoria (\%) }\end{array}$ \\
\hline Forza Italia & 61 & 37,8 & 34,1 & 3,7 & 38 & 62,3 \\
Lega Nord & 148 & 41,1 & 37,7 & 3,4 & 107 & 72,3 \\
Ccd & 15 & 34,1 & 32,0 & 2,1 & 8 & 53,3 \\
Udc & 3 & 49,6 & 41,8 & 7,8 & 3 & 100,0 \\
Riformatori & 6 & 47,8 & 43,0 & 4,8 & 6 & 100,0 \\
Pld & 2 & 49,7 & 43,1 & 6,6 & 2 & 100,0 \\
Polo Libertà & 235 & 40,1 & 36,7 & 3,4 & 164 & 69,8 \\
& & & & & & \\
Forza Italia & 63 & 35,9 & 35,6 & 0,3 & 36 & 57,1 \\
An & 102 & 37,8 & 34,5 & 3,3 & 79 & 77,5 \\
Ccd & 21 & 38,8 & 37,7 & 1,1 & 13 & 61,9 \\
Udc & 1 & 30,4 & 33,9 & $-3,5$ & 1 & 100,0 \\
Polo Buon Gov. & 187 & 37,2 & 35,2 & 2,0 & 129 & 69,0 \\
\hline
\end{tabular}

1 Calcolata sui votanti.

mo dato potrebbe essere influenzato dalla qualità dei collegi in cui i candidati di An erano presenti, ma questa spiegazione non basta perché il dato sui voti di lista - che è un indicatore sensibile della qualità dei collegi - ci dice che non esistono sostanziali differenze tra i collegi assegnati ai candidati delle varie componenti del Pbg.

In sintesi, il quadro che emerge dai dati del $\mathrm{Pbg}$ è quello di An come forza trainante del polo. In parte può avere contribuito a questo risultato il maggiore radicamento sociale di An rispetto a Fi e/o la maggiore visibilità dei suoi candidati. Ma ciò non toglie che il dato più sorprendente è l'assenza di un voto ideologico all'interno del cartello di destra. La presentazione di candidati apparentemente più estremi non danneggia lo schieramento, anzi sembra favorirlo. È come se non esistesse nessuna pregiudiziale ideologica all'interno dell'elettorato di destra nei confronti di An. A differenza della sinistra quindi i voti della destra - quanto meno al Sud perché è di questa zona che stiamo parlando trattandosi di $\mathrm{Pbg}$ - sono più sommabili. Evidentemente gli elettori potenziali del $\mathrm{Pbg}$ percepiscono una minore 
distanza ideologica tra le sue componenti tale da rendere le loro candidature non solo intercambiabili, $\mathrm{ma}$ in qualche caso addirittura più attraenti di quelle di altri partiti al di fuori del polo. Il voto ideologico non è un problema della destra. Semmai, come abbiamo visto precedentemente, il problema della destra si chiama voto disperso.

\section{Conclusioni}

Le regole maggioritarie hanno funzionato. Se i deputati fossero 475 e i senatori 232, cioè se non ci fosse quota proporzionale, oggi in Parlamento ci sarebbe una maggioranza politica solida (almeno numericamente) sia alla Camera che al Senato. Infatti, i Poli (Polo delle libertà, Polo del buon governo e loro varianti) hanno ottenuto il $63,6 \%$ dei seggi uninominali alla $\mathrm{Ca}$ mera e il $55,2 \%$ al Senato. Questo è in sintesi il risultato della competizione maggioritaria.

La situazione reale invece è quella di un Parlamento diviso. Al Senato la maggioranza dei seggi uninominali della destra è diventata minoranza. Perché? La prima e più diretta causa del Parlamento diviso è certamente la diversità del sistema elettorale tra Camera e Senato. Lo scorporo totale al Senato ha danneggiato la parte vincente (i Poli) più che lo scorporo parziale della Camera. Ma esiste una causa più importante che sta a monte del processo di «riduzione a minoranza» operato dallo scorporo ai danni della destra: il diverso rendimento dei due maggiori schieramenti all'interno della competizione maggioritaria. Fermo restando che il terzo schieramento in gara (il Patto per l'Italia) si è rivelato non competitivo sia alla Camera che al Senato, se i Poli di destra avessero ottenuto al Senato la stessa percentuale di seggi che hanno ottenuto alla Camera, il Parlamento non sarebbe oggi diviso. Allora, perché i Poli hanno vinto meno al Senato? E per converso perché i Progressisti hanno vinto di più? Tra l'altro, questa domanda nasconde un paradosso: la destra era divisa in certe circoscrizioni alla Camera, ma non al Senato. Eppure ha vinto di più alla Camera.

In questo saggio abbiamo cercato di rispondere partendo dalla analisi della competitività degli scontri maggioritari. Sono emersi tre risultati generali. Il primo concerne le differenze territoriali. Le elezioni maggioritarie hanno dimostrato chiaramente sia alla Camera che al Senato che il Paese è diviso in tre zone 
di cui due non competitive (il Nord egemonizzato dalla destra e il Centro dalla sinistra) e una sola - il Sud - competitiva. Soglie di vittoria e distanza tra i primi due candidati sono gli indicatori che abbiamo utilizzato per fissare questa mappa della competitività.

Il secondo risultato verte sulle differenze Camera-Senato. Il Senato si è rivelato più competitivo della Camera. Scartando «l'ipotesi voto giovanile», questo risultato può essere spiegato facendo riferimento 1) alla maggiore quota di voti ottenuti dalla sinistra al Sud rispetto al Nord (sia alla Camera che al Senato); 2) alla maggiore frammentazione del voto al Senato rispetto alla Camera; 3) alla diminuzione dei voti ai candidati di destra al Senato (a causa della frammmentazione di cui al punto 2) che ha creato una situazione di maggiore competitività al Sud.

L'ultimo risultato riguarda la coesione elettorale degli schieramenti politici. La possibilità di confrontare alla Camera i voti proporzionali alle liste con $i$ voti ai candidati nei collegi ci permette di «misurare» in un certo senso le reazioni degli elettori alle candidature delle diverse formazioni politiche che compongono ciascun cartello e quindi la compatibilità del suo elettorato. Questo confronto ha messo in luce come il voto alle liste di sinistra sia sistematicamente maggiore del voto ai suoi candidati. Il contrario vale per la destra. Mentre la destra riesce a mobilitare tutto il suo serbatoio di voti potenziali a favore dei suoi candidati nei collegi, questo non riesce alla sinistra. Abbiamo attribuito questo fenomeno alla diffusione e persistenza a sinistra di un «voto ideologico» che fatica ad accettare candidati che non siano i «propri». L'ideologia favorisce l'appartenenza, ma irrigidisce la trasferibilità del voto (la sua elasticità) che in un contesto di regole maggioritarie è una delle chiavi del successo. Questo rende i voti di sinistra meno «sommabili» dei voti della destra contribuendo così ad una minore competitività della sinistra soprattutto con un sistema maggioritario.

$\mathrm{Ma}$ al di là del voto ideologico, del voto strategico e delle defezioni elettorali ad essi imputabili, l'altro - grave - problema della sinistra è la mancanza di voti. Essa è scarsamente competitiva (tranne al Centro) perché il suo serbatoio di voti è modesto. Il dato più clamoroso di queste elezioni è la percentuale dei voti ai candidati e alle liste di sinistra (tutta la sinistra!) al Nord: rispettivamente il $25 \%$ e il $25,7 \%$ (alla Camera). Ma anche al Sud (dove le cose sono andate meglio) la sinistra può contare solo su poco più del $30 \%$ dei voti. Nemmeno con que- 
sta percentuale si può essere sicuri di vincere con regole maggioritarie. Questa volta la sinistra ha ottenuto relativamente molti seggi al Sud (ed ha evitato così una vera e propria disfatta) perché la destra era divisa e perché l'elettorato di destra si è disperso. Ma questi fattori sono di per sé aleatori. La realtà è che, con la distribuzione attuale degli orientamenti di fondo dell'elettorato e quindi escludendo radicali modifiche, la destra può contare almeno al Sud su ampi margini di miglioramento grazie ad una considerevole riserva potenziale di voto disperso tendenzialmente moderato. Al contrario, la sinistra sembra aver esaurito il suo serbatoio di voti e di alleati. Non solo. Essa sembra addirittura incapace di mobilitare tutto il suo elettorato. È vero che $i$ voti sono pochi in partenza, che la sua base elettorale è limitata, ma la «fedeltà » dei suoi elettori è, ciononostante, una delle condizioni necessarie per vincere. Invece, non è così. Il «male oscuro» delle sinistra italiana sta anche qui. Senza coesione elettorale, nel senso che abbiamo dato qui a questo termine, nemmeno una base del $40 \%$ dei voti è sufficiente per vincere. Ecco perché il problema della «sommabilità » dei voti di sinistra è importante tanto quanto quello della ricerca di nuovi voti.

Certo, il mercato elettorale oggi è molto piu aperto di quanto non fosse prima (Diamanti e Mannheimer 1994, Sani 1992). La maggiore elasticità del voto, combinata all' «effetto leva» del sistema maggioritario, lascia la porta aperta a risultati anche radicalmente diversi alle prossime elezioni. Ma difficilmente questo potrà accadere se la sinistra non sarà in grado di essere più competitiva. E senza una sinistra competitiva il sistema partitico italiano è destinato a restare, come è stato finora, non competitivo.

\section{Riferimenti bibliografici}

Agosta, A. (1994), Maggioritario e proporzionale, in I. Diamanti e R. Mannheimer (1994), pp. 15-28.

Bartolini, S. e P. Mair (1990), Identity, Competition, and Electoral Availability, Cambridge, Cambridge University Press.

Chiaramonte, A. (1994), Gli effetti distorsivi del nuovo sistema elettorale, in «Rivista Italiana di Scienza Politica», in questo stesso numero, infra, pp. 687-714.

D'Alimonte, R. (1994), L'uninominale incompiuto, in «Il Mulino», XLIII, pp. 55-62. 
D'Alimonte, R. e A. Chiaramonte (1993), Il nuovo sistema elettorale italiano: quali opportunità?, in «Rivista Italiana di Scienza Politica», XXIII, pp. 513-547.

Diamanti, I. (1994), I Mezzogiorni, in Diamanti e Mannheimer (1994), pp. 127-134.

Diamanti, I. e R. Mannheimer (a cura di) (1994), Milano a Roma. Guida all'Italia elettorale del 1994, Roma, Donzelli.

Di Virgilio, A. (1994), Dai partiti ai poli: la politica delle alleanze, in «Rivista Italiana di Scienza Politica», in questo stesso numero, supra, pp. 493-547.

Natale, P. (1994), La nuova mappa geo-politica, in Diamanti e Mannheimer (1994), pp. 85-98.

Ricolfi, L. (1994), Il voto proporzionale: il nuovo spazio politico italiano, in «Rivista Italiana di Scienza Politica», in questo stesso numero, supra, pp. 587-629.

Sani, G. (1992), 1992: la destrutturazione del mercato elettorale, in «Rivista Italiana di Scienza Politica», XXII, pp. 539-565. 